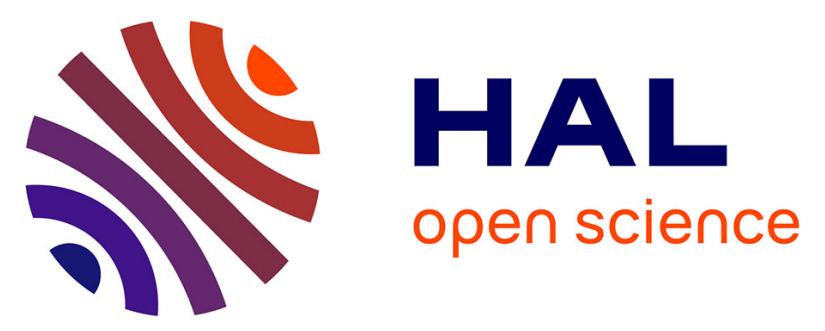

\title{
Quantified Binding Scale of Competing Ligands at the Surface of Gold Nanoparticles: The Role of Entropy and Intermolecular Forces
}

Claire Goldmann, François Ribot, Leonardo F. Peiretti, Paola Quaino, Frederik Tielens, Clément Sanchez, Corinne Chanéac, David Portehault

\section{To cite this version:}

Claire Goldmann, François Ribot, Leonardo F. Peiretti, Paola Quaino, Frederik Tielens, et al.. Quantified Binding Scale of Competing Ligands at the Surface of Gold Nanoparticles: The Role of Entropy and Intermolecular Forces. Small, 2017, 13 (20), pp.1604028 10.1002/smll.201604028 . hal-01517528

\section{HAL Id: hal-01517528 \\ https://hal.sorbonne-universite.fr/hal-01517528}

Submitted on 3 May 2017

HAL is a multi-disciplinary open access archive for the deposit and dissemination of scientific research documents, whether they are published or not. The documents may come from teaching and research institutions in France or abroad, or from public or private research centers.
L'archive ouverte pluridisciplinaire HAL, est destinée au dépôt et à la diffusion de documents scientifiques de niveau recherche, publiés ou non, émanant des établissements d'enseignement et de recherche français ou étrangers, des laboratoires publics ou privés. 
DOI: $10.1002 /(($ please add manuscript number $))$

Article type: Full Paper

Quantified Binding Scale of Competing Ligands at the Surface of Gold Nanoparticles: the Role of Entropy and Intermolecular Forces

Claire Goldmann, ${ }^{a}$ François Ribot, ${ }^{a}$ Leonardo F. Peiretti, ${ }^{b}$ Paola Quaino, ${ }^{b}$ Frederik Tielens, ${ }^{a}$ Clément Sanchez, ${ }^{a}$ Corinne Chanéac, ${ }^{a}$ and David Portehault ${ }^{a}, *$

Dr. C. Goldmann, Dr. F. Ribot, Dr. F. Tielens, Prof. C. Sanchez, Dr. C. Chanéac, Dr. D. Portehault

Sorbonne Universités, UPMC Univ Paris 06, CNRS, Collège de France, Laboratoire de Chimie de la Matière Condensée de Paris (CMCP), 11 place Marcelin Berthelot, F-75005, Paris, France

E-mail: david.portehault@upmc.fr

Dr. L. F. Peiretti, Dr. P. Quaino

Preline, Facultad de Ingeniería Química, Universidad Nacional del Litoral, 3000, Santa Fe, Argentina

\section{Keywords:}

Gold nanoparticles,

Multifunctional nanoparticles,

Ligand exchange,

Nuclear Magnetic Resonance,

Density Functional Theory 


\section{ABSTRACT}

Basic understanding of the driving forces for the formation of multi-ligand coronas, or selfassembled monolayers, over metal nanoparticles is mandatory to control and predict the properties of ligand-protected nanoparticles. Herein we combine ${ }^{1} \mathrm{H}$ nuclear magnetic resonance experiments and advanced DFT modelling to highlight the key parameters defining the efficiency of ligand exchange on dispersed gold nanoparticles. The compositions of the surface and of the liquid reaction medium are quantitatively correlated for bi-functional gold nanoparticles protected by a range of competing thiols, including an alkylthiol, arylthiols of varying chain length, thiols functionalized by ethyleneglycol units and amide groups. These partitions are used to build scales that quantify the ability of a ligand to exchange dodecanethiol. Such scales can be used to target a specific surface composition by choosing the right exchange conditions (ligand ratio, concentrations, particle size). In the specific case of arylthiols, the exchange ability scale is exploited with the help of DFT modelling to unveil the roles of intermolecular forces and entropic effects in driving ligand exchange. We finally suggest that similar considerations may apply to other ligands and to direct bi-ligand synthesis. 


\section{Introduction}

Surface functionalization is a pillar of modern colloidal science focusing on nanostructures. For instance, using organic molecules as surface complexing agents, so-called ligands, on gold nanoparticles allows introducing and managing functionality in application fields such as sensors $^{[1]}$ or biomedicine. ${ }^{[2-4]}$ Such capping agents can also be adequately chosen and introduced during colloidal synthesis to control the growth of nanoparticles and then to tune their size, shape and dispersion state. ${ }^{[5-7]}$ In most cases, the ligand shell, or self-assembled monolayer (SAM), is actually constituted of several ligands so as to provide multifunctionality, ${ }^{[4,8-11]}$ or to ensure functionalization by given moieties, ${ }^{[12,13]}$ while other ligands with simple hydrophobic or hydrophilic chains provide colloidal stability in organic or aqueous media, respectively.

Bi-functional nanoparticles can be obtained by two methods: ligands exchange, where particles first synthesized with ligands $\mathbf{A}$ only are processed in solution to exchange a fraction of A by ligands B (Figure 1a); and bi-ligands synthesis, where the particles are directly synthesized in contact with ligands A and B (Figure 1b).

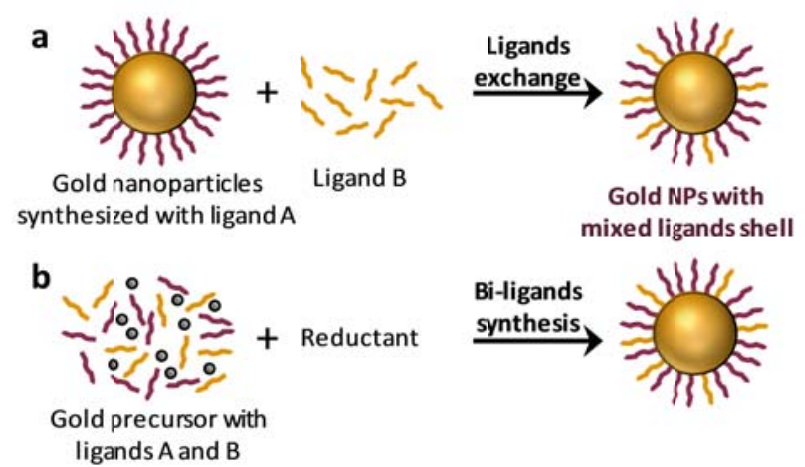

Figure 1. The two pathways used to obtain nanoparticles with mixed ligands shell: (a) ligand exchange and (b) bi-ligands synthesis.

In both cases, the main difficulty is to control the final composition of the ligand shell. In order to understand, ${ }^{[10,14-17]}$ control $^{[18]}$ and predict ${ }^{[19]}$ the properties of such very common, yet complex, hybrid nanoparticles made of an inorganic core and a bi-component organic corona, the composition of the shell must be assessed. Various methods can unveil the 
composition of bi-ligands shells, such as mass spectrometries, ${ }^{[20,21]}$ electron paramagnetic resonance, ${ }^{[22]}$ fluorescence, ${ }^{[4,23]}$ and surface enhanced Raman spectroscopies. ${ }^{[2]}$ Liquid state NMR is also a versatile tool to quantify the ligand shell composition for a range of molecules and inorganic cores, ${ }^{[25-29]}$ to study the ligand surface distribution, ${ }^{[25,29-32]}$ and the exchange dynamics. ${ }^{[33-36]}$ Among these state-of-the art studies, only few correlate together the shell and medium compositions at the steady-state ${ }^{[24,26,37]}$ or during the exchange process. ${ }^{[35,36]}$

Extending to other ligands and particle sizes the quantification at the steady-state of the molecular partition between mixed ligand shells and the surrounding medium should provide two significant advances. First, quantified partition could be used to predict the composition of the mixed SAM for a given ligand ratio in the initial solution, and even to select the right initial ratio to reach a targeted surface composition. Second and more fundamentally, quantifying the partition for a series of well-chosen ligands should provide new insights into the role of the chain length and functionality, ${ }^{[16,17,19,38-44]}$ and of the endgroup, ${ }^{[28,29,45,46]}$ on ligands exchange and the stability of mixed ligand shells. In brief, such quantified partitions may contribute to decipher the impact of intermolecular forces and entropic effects on the stability of the ligands shells and their role as driving forces for ligands exchange, a topical issue for the control of nanoparticles properties and self-assembly. ${ }^{[4,8-}$ $13,41,47-49]$

Herein we focus on the influence of the ligands molecular structure on the final surface composition of ligand-capped gold nanoparticles. We use NMR to investigate ligand exchange for a range of thiol ligands and build quantitative scales of molecular partition as a measure of the exchange ability for each ligand. We especially investigate a series of arylthiols by coupling experiments with DFT modelling, in order to interpret in depth the molecular principles underlying ligands exchange for these molecules. We investigate indepth the prime importance of intermolecular chain interactions in the stabilization and 
composition of mixed ligands shells on nanoparticles, and shed a new light on the role of entropic effects. We then extend the approach to other ligands and to bi-ligands syntheses.

\section{Results and discussion}

The thiol ligands used in this study (Figure 2) differ by the functionalities of their chain. DDT contains only $\mathrm{CH}_{2}$ units. $\mathrm{Ph}, \mathrm{BiPh}$ and TerPh contain 1, 2 and 3 aromatic phenyl groups, respectively. In a second step, two ligands (TegA and Teg) containing several ethyleneglycol units are investigated. The TegA ligand contains also an alkyl spacer and an amide function. Each ligand provides different preponderant intermolecular forces, originating from dispersion, van der Waals or dipolar interactions, H-bonding or $\pi$-stacking.

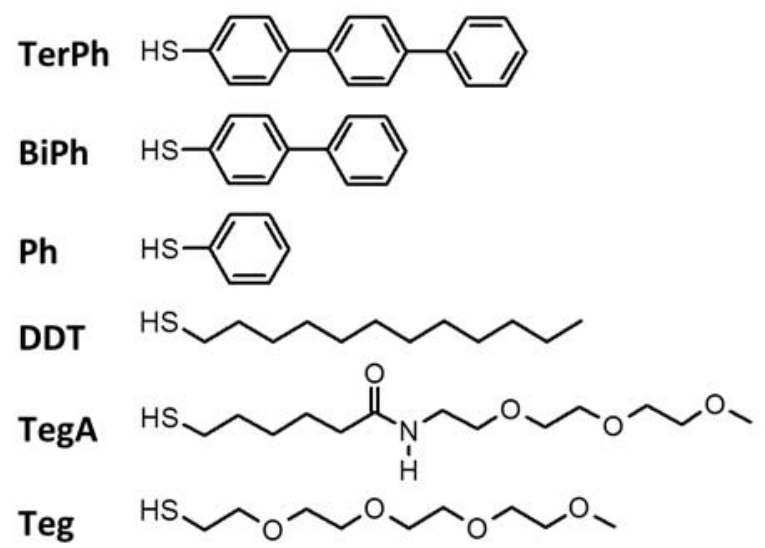

Figure 2. Molecular structures of the ligands used in this study.

\subsection{Determination of the surface composition: the case study of dodecanethiol/p- terphenylthiol mixed ligand corona}

When a ligand is grafted onto the surface of a nanoparticle, its NMR signals are broadened because of the distribution of local environments, which spread the associated chemical shifts, and because of shorter transverse relaxation times, which arise from a decrease of its rotational mobility (degrees of freedom). ${ }^{[50]}$ This broadening, which increases with the proximity of the surface, can be so important that the signal completely flattens out in the baseline, ${ }^{[51,52]}$ as observed for the $\mathrm{CH}_{2} \mathrm{~S}$ moieties, the closest to the surface, in aliphatic thiolstabilized gold particles. ${ }^{[53]}$ On the contrary, free ligands yield sharp NMR signals. This difference was used to monitor ligands exchange. Figure 3 shows portions of the ${ }^{1} \mathrm{H}$ NMR 
spectra of a suspension of $2 \mathrm{~nm}$ DDT-stabilized nanoparticles during the exchange with TerPh (full spectra shown in Figure S1) with a total TerPh proportion of $52 \mathrm{~mol}$. \%. No particle size evolution was detected by TEM (Figure S2) after $110 \mathrm{~h}$. The sharp signall at $3.50 \mathrm{ppm}$ of the thiol proton of free TerPh ( $\mathbf{a}^{\prime}$ in Figure 3) appears after the addition of TerPh and then slowly decreases upon grafting of TerPh. The DDT quadruplet at $2.52 \mathrm{ppm}$ (b in Figure 3), corresponding to the $\alpha-\mathrm{CH}_{2}$ next to the sulfur atom, concomitantly grows immediately after the addition of TerPh.

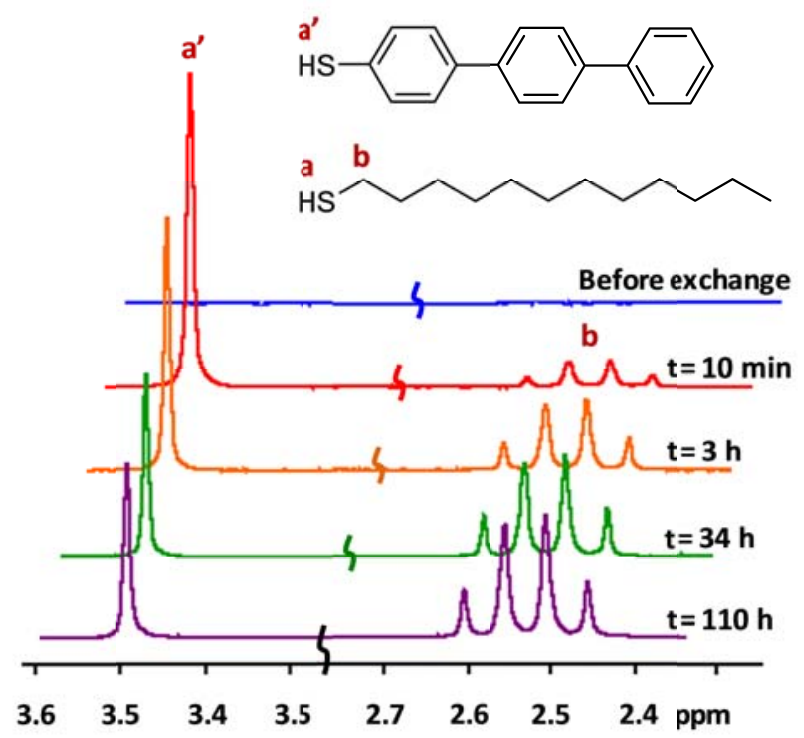

Figure 3. Time evolution of specific ${ }^{1} \mathrm{H}$ NMR signals during the exchange of DDT by TerPh (total TerPh proportion of $52 \%$ ), in $\mathrm{CDCl}_{3}$, at a nanoparticles concentration of $10^{-4} \mathrm{M}$ for a particle diameter of $2 \mathrm{~nm}$.

Upon release of DDT, integration of these signals yields the relative amounts of free ligands. By using the ${ }^{1} \mathrm{H}$ NMR spectrum of a blank solution of known concentration and volume acquired in the same conditions, the integrations are converted in absolute quantities of free species, yielding the time evolution represented in Figure 4. Once the ${ }^{1} \mathrm{H}$ NMR spectra do not change anymore (110 h for DDT/TerPh couple), all thiol species are converted into free disulfides with the "iodine death reaction". ${ }^{[54]}$ The total amount of DDT in the reaction medium ( $\left.\mathrm{DDT}_{\text {total }}\right)$, which corresponds to the initial quantity of bonded DDT, is determined 
by integration. The surface composition at a given time is then derived with the following simple relations:

$\mathrm{DDT}_{\text {grafted }}(t)=\mathrm{DDT}_{\text {total }}-\mathrm{DDT}_{\text {solution }}(t)$

$\operatorname{TerPh}_{\text {grafted }}(t)=\mathrm{TerPh}_{\text {added }}-\mathrm{TerPh}_{\text {solution }}(t)$

$\mathrm{DDT}_{\text {solution }}(t)$ and $\mathrm{TerPh}_{\text {solution }}(\mathrm{t})$ being the quantities of free DDT and free TerPh at a given time, respectively. The maximal uncertainty of these quantity measurements was evaluated to $\sim 2 \%$ (see supplementary information).

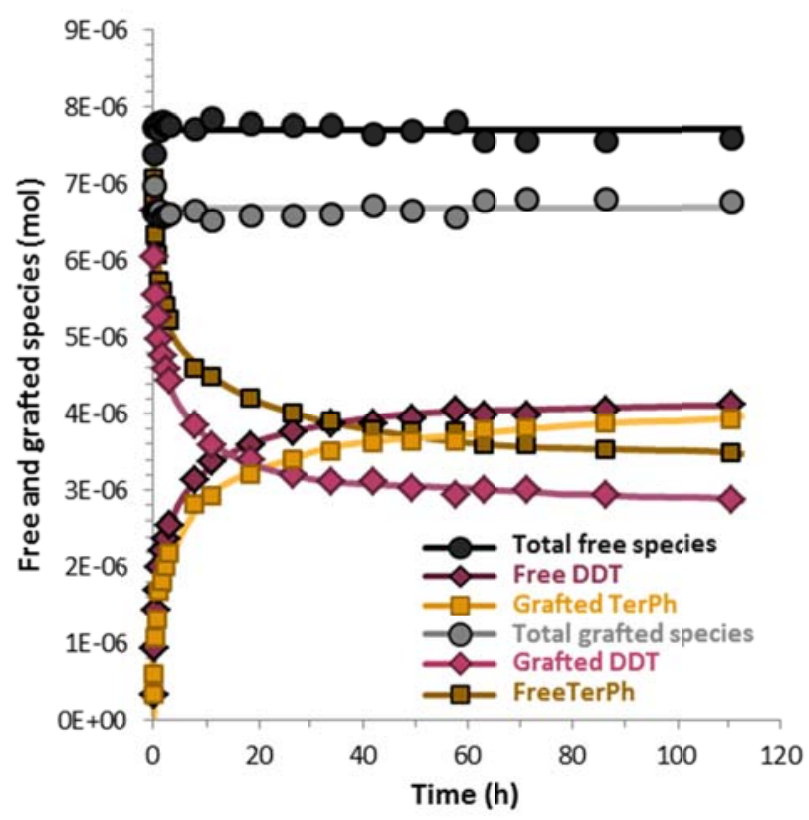

Figure 4. Time evolution of the amounts of each free and grafted species during the exchange of DDT by TerPh (total TerPh proportion of $52 \%$ ), in $\mathrm{CDCl}_{3}$, at a nanoparticles concentration of $10^{-4} \mathrm{M}$ for a particle diameter of $2 \mathrm{~nm}$.

The time evolution of each grafted species at a nanoparticles concentration of $10^{-4} \mathrm{M}$ is reported in Figure 4. The total quantities of grafted and free species remain constant, suggesting that the exchange of DDT by TerPh occurs with a 1:1 stoichiometry, as mentioned in previous works on different thiols. ${ }^{[38]}$ The overall reaction can be written:

$D D T_{\text {surface }}+B_{\text {solution }} \rightleftarrows D D T_{\text {solution }}+B_{\text {surface }}$

In few cases, mostly with the TegA ligand but not with arylthiols, a change in the particle size was evidenced. Accordingly, even if the 1:1 stoichiometry is respected, a slight increase in the 
quantity of grafted species is observed in agreement with the increase of gold surface area

(Figure S3b).

The grafting density of the initial DDT monolayer was evaluated from the quantity of grafted ligands and the geometrical surface of the particles. A coverage of about 5 thiols $\cdot \mathrm{nm}^{-2}$ is obtained, which is consistent with the literature ${ }^{[55]}$ and in agreement with the slight variations in particle size observed in the size distributions (Figures S4, S5). As the exchange proceeds through a 1:1 stoichiometry, grafting densities are constant and similar in all experiments.

Noteworthy, the same coverage value of $\sim 5$ thiols $\cdot \mathrm{nm}^{-2}$ and exchange stoichiometry are measured on $2 \mathrm{~nm}$ and $5 \mathrm{~nm}$ particles for all ligands considered in this study. Furthermore, TEM observations yield similar spherical nanoparticle shapes for all exchange experiments (Figures S4-S6).

\subsection{Partition ratios: building the ligands exchange efficiency scale}

The procedure described above was applied to both 2 and $5 \mathrm{~nm}$ diameter nanoparticles initially stabilized by DDT. The exchanges were carried out with ligands $\mathrm{Ph}, \mathrm{BiPh}, \mathrm{TerPh}$, TegA and Teg added in various amounts. ${ }^{1} \mathrm{H}$ NMR was used to monitor specific signals: $\mathrm{CH}_{2} \mathrm{~S}$ at $2.52 \mathrm{ppm}$ for DDT, $\mathrm{SH}$ at $3.50 \mathrm{ppm}$ for $\mathrm{Ph}, \mathrm{BiPh}$ and $\mathrm{TerPh} ; \mathrm{CH}_{2} \mathrm{~S}$ at $2.70 \mathrm{ppm}$ for Teg; and $\mathrm{CH}_{2} \mathrm{~S}$ at $2.54 \mathrm{ppm}$ for TegA. In the latter case, a deconvolution step was necessary to separate free DDT from free TegA.

For a given $\mathrm{B}$ species $(\mathrm{Ph}, \mathrm{BiPh}, \mathrm{TerPh}, \mathrm{TegA}$ or Teg), the compositions of the whole reaction medium $\left(\% B_{\text {medium }}\right)$ and of the nanoparticles surface $\left(\% B_{\text {surface }}\right)$ at the steady state are calculated from the NMR titration curves as follows:

$$
\begin{aligned}
& \% B_{\text {medium }}=100 \frac{\text { quantity of } B \text { in solution and grafted }}{\text { quantity of } A \text { and } B \text { in solution and grafted }} \\
& \% B_{\text {surface }}=100 \frac{\text { quantity of } B \text { grafted }}{\text { quantity of } A \text { and } B \text { grafted }}
\end{aligned}
$$


Figure 5a shows a partition diagram for $\mathrm{Ph}, \mathrm{BiPh}$ and $\mathrm{TerPh}$ where the surface composition is plotted versus the composition of the whole reaction medium for every ligand couple considered. Apart from few exceptions, no point is placed on the diagonal. The composition of the surface nearly never equals the composition of the reaction medium.

We define the partition coefficient of each ligand at the steady state:

$P_{\text {ligand }}=\frac{\text { proportion of ligand in the grafted shell }}{\text { concentration of ligand in solution }}$

For the exchange of DDT by ligand $\mathrm{B}$, one can define the partition ratio $R_{B}$ :

$R_{B}=\frac{P_{B}}{P_{D D T}}=\frac{\sigma(B)[D D T]_{\text {solution }}}{\sigma(D D T)[B]_{\text {solution }}}$

Where $\sigma(\mathrm{B})$ and $\sigma(\mathrm{DDT})$ are the proportions of $\mathrm{B}$ and DDT at the surface, respectively. $\% \mathrm{~B}_{\text {surface }}$ can then be expressed as a function of $\% \mathrm{~B}_{\text {medium }}$ using $R_{B}$ as a parameter (not shown). Note that in the case of equilibrium between the surface and the solution, $R_{B}$ coincides with the equilibrium constant of equation (3), as already derived from competitive Langmuir isotherms. ${ }^{[24]}$ Fitting the experimental data (Figure 5a) yields $R_{B}$ values for the different systems. The scale of partition ratios $R_{B}$ provides a measurement of the ability for each ligand to exchange DDT ligands (Figure 5b). As expected, the nature of the chain impacts the exchange. For nanoparticles of $5 \mathrm{~nm}$ diameter, the more aromatic groups, the higher the affinity for the surface: $R_{\text {TerPh }}>R_{B i P h}>R_{P h}$. This finding is consistent with previous observations, which evidenced the role of the alkylthiol chain length on the exchange, namely a stabilization of the ligand shell for longer chains that yield increased interchain interaction. ${ }^{[38]}$ The origin of this behavior is discussed in details below. 

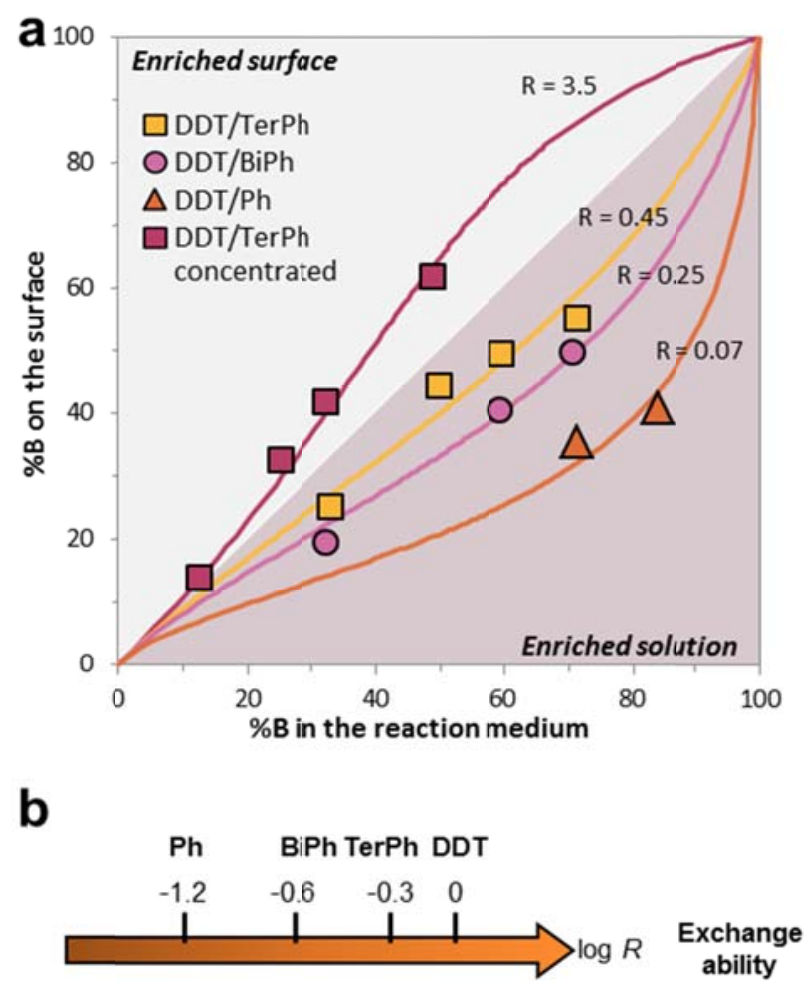

Figure 5. (a) Partition of $\mathrm{B}$ ligands (TerPh, $\mathrm{BiPh}$ and $\mathrm{Ph}$ ) on $5 \mathrm{~nm}$ nanoparticles for different DDT/B ligands couples in chloroform at particle concentrations of $3 \cdot 10^{-7} \mathrm{M}$, and also $10^{-4} \mathrm{M}$ for TerPh. (b) Exchange ability scale of $\mathrm{Ph}, \mathrm{BiPh}$, TerPh ligands versus DDT in $3 \cdot 10^{-7} \mathrm{M}$ $\mathrm{CDCl}_{3}$ suspensions.

\subsection{Role of the ligand functionality on the exchange: deciphering the arylthiols series by DFT calculations}

Figure 5 shows that $\mathrm{TerPh}, \mathrm{BiPh}$ and $\mathrm{Ph}$ do not have the same capacity to displace DDT, with binding efficiencies against DDT in the order of $\mathrm{TerPh}>\mathrm{BiPh}>\mathrm{Ph}$. Modifying the chain may impact ligand binding by changing intermolecular interactions in the SAM, the gold-sulfur interaction through e.g. electron-donation/withdrawal, and entropic effects. Each phenomenon is considered below as the potential origin of the differences in exchange ability.

\subsubsection{Entropy balance in the arylthiols series}

In the process of ligand exchange, entropy may impact (1) the free energy of the final DDT/TerPh SAM versus the initial SAM, but also (2) the free energy of solubilized ligands in the surrounding solvent. In the first case, Glotzer, Stellacci and co-workers ${ }^{[16,17,19,41-43]}$ 
showed that energetically, different distributions of the ligands at the surface differ mostly by their entropy. Especially, stabilization of the mixed SAM versus the pure (initial) SAM can occur by entropic effects. Arylthiols have been shown to be relatively homogeneously distributed in a mixed alkyl/arylthiols SAM on $5 \mathrm{~nm}$ particles, ${ }^{[41-43]}$ so that configurational entropy (mixing entropy) ${ }^{[16,17,19,41-44]}$ is similar for $\mathrm{TerPh}, \mathrm{BiPh}$ and $\mathrm{Ph}$ and does not discriminate these systems. Stabilization of mixed SAMs by conformational entropy (interface entropy originating from the free volume available for the longest ligand chains next to shorter ligands $)^{[16,17,19,41-44]}$ at the interface between two ligands has also been demonstrated. This contribution is negligible for two ligands of similar length (as in the DDT/TerPh system, molecular lengths of $\sim 1.8$ and $1.7 \mathrm{~nm}$ for DDT and $\mathrm{TerPh}^{[56]}$ respectively), but increases with the difference in length between both ligands. It has been observed on $5 \mathrm{~nm}$ nanoparticles for arylthiols ${ }^{[42,43]}$ and supported by calculations on other systems. ${ }^{[19,41]}$ This effect should stabilize the mixed SAMs in the order: $\mathrm{TerPh}<\mathrm{BiPh}<\mathrm{Ph}$, in opposition to experimental results (Figure 5). In the second case related to the solubilized ligands, upon the 1:1 ligand exchange, the incoming arylthiol ligand loses entropy in the SAM, while the DDT molecule released in the solvent gains entropy. For molecules $\mathrm{TerPh}, \mathrm{BiPh}$ and $\mathrm{Ph}$ with similar rigidity, in a given solvent and with a given particle size, the entropic balance during the exchange should be similar and cannot account for the different surface affinities. In the following part, we address the two other potential origins (gold-sulfur bond strength and intermolecular interactions) by comparing the experimental results (Figure 5) with DFT calculations on models of SAMs on flat $\mathrm{Au}(111)$ substrates for each DDT/arylthiol couple.

\subsubsection{Model SAMs}

The DDT SAM was constructed according to a common model (Figure S7, details in SI). For arylthiols, different SAMs configurations are expected to be stable depending on the 
experimental conditions: ${ }^{[56,57]}$ the parallel adsorption geometry via $\pi-\pi$ interactions on unreconstructed gold, or the paired adsorption via $\sigma-\pi$ interactions on surface gold adatoms (“T-shaped"). From DFT calculations (not shown for the parallel configuration), the T-shaped configuration is slightly more stable at the same TerPh coverage. We then opted for the latter configuration (Figure 6a and details in SI), in agreement with previous STM observations on flat $\mathrm{Au}(111)$ surfaces. ${ }^{[56]}$

The adsorption energy of one thiol chain $\left(\Delta E_{\text {ads }}\right)$ in a perfectly ordered SAM is the sum of the binding energy from the sulfur-gold bond $\Delta E_{\text {bind(S-Au) }}$ and the intermolecular interactions $\Delta E_{\text {int.chain }}$ (including dispersion (London) interactions) between the molecules forming the SAM:

$\Delta E_{\mathrm{ads}}=\Delta E_{\mathrm{bind}(\mathrm{S}-\mathrm{Au})}+\Delta E_{\text {int.chain }}$

$\Delta E_{\text {ads }}$ and $\Delta E_{\text {bind(S-Au) }}$ were evaluated independently by DFT calculations, in order to retrieve $\Delta E_{\text {int.chain }}$ (details in the methods section). Briefly, $\Delta E_{\text {ads }}$ was calculated as the difference between the electronic energy of the SAM and the electronic energies of the free components (thiyl radicals and $\mathrm{Au}(111)$ substrate), to which was added the dispersion interaction energy calculated by using a semi-empirical dispersion potential with a DFT approach. ${ }^{[58]} \Delta E_{\text {bind(S-Au) }}$ was evaluated by a similar approach on a highly diluted SAM. Figure 6b shows the adsorption energies for pure DDT, TerPh, BiPh and Ph SAMs calculated with (PBE-D3) and without (PBE) dispersion interactions. The adsorption energy at the PBE-D3 level was also calculated for a mixed DDT/TerPh SAM in a 1/1 ratio (Figure 6b). At the pure PBE level for arylthiols, the intermolecular interactions are calculated to be repulsive. This incorrect result stems from the omission of stabilizing dispersion intermolecular interactions in the assembly at the PBE calculation level. In order to correct this point, we have performed calculations at a more advanced level, by taking into account dispersion interactions, of prime importance when interactions between aromatic groups or alkyl chains are at play. This refinement does 
not impact significantly the Au-S binding energy binding trend, i.e. almost constant within the arylthiol series $( \pm-2.10 \mathrm{eV})$, but the contribution of intermolecular interactions is radically modified and becomes attractive, as expected. This result validates our procedure for taking into account dispersion interactions. ${ }^{[59]}$

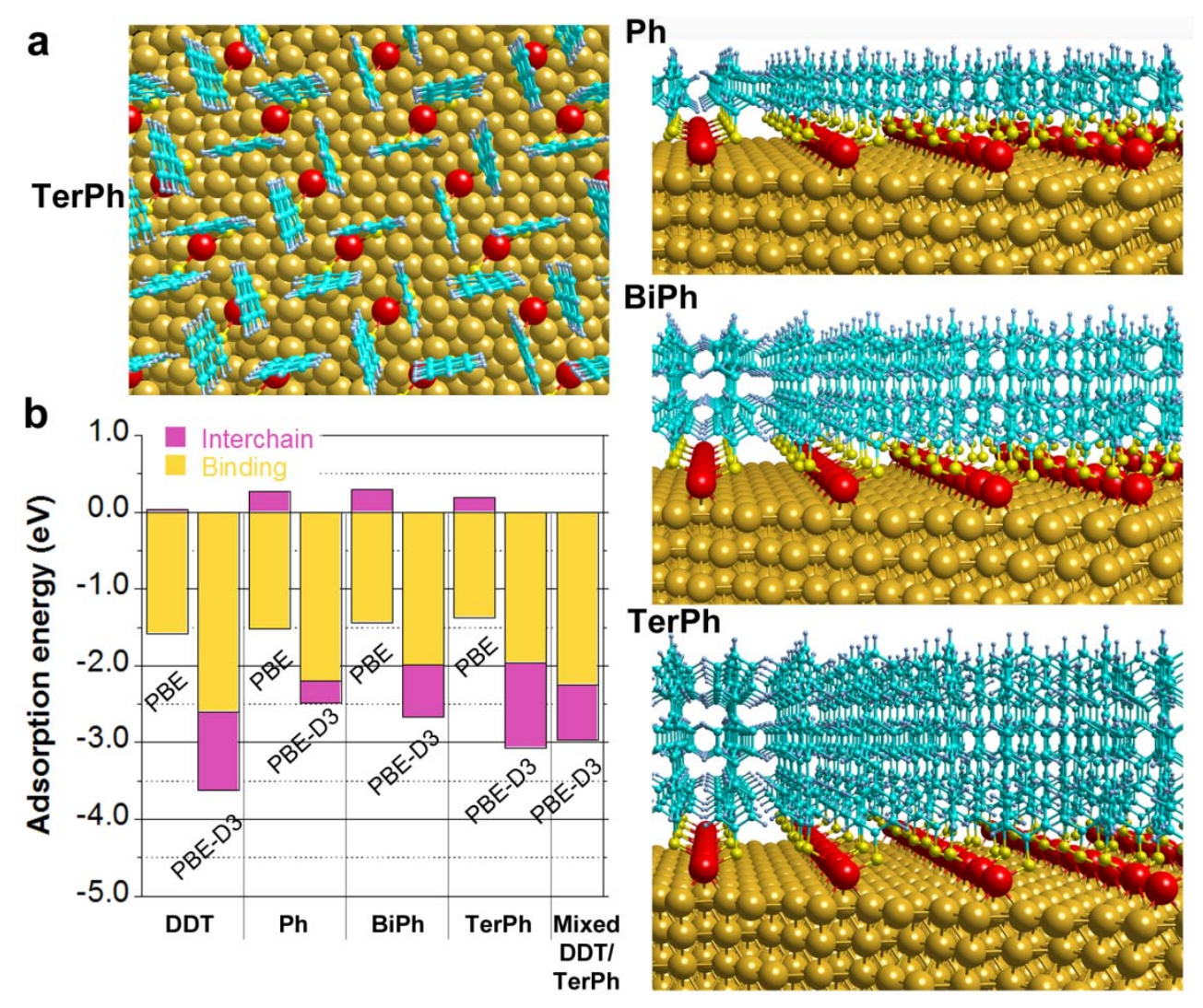

Figure 6. (a) Top view of the SAM model for TerPh thiols. Bright yellow: $\mathrm{S}$ atoms; blue: $\mathrm{C}$ atoms; white: $\mathrm{H}$ atoms; dark yellow: gold atoms of the bulk substrate; red: gold adatoms formed by the chemisorption of the arylthiols. On the right: side views for $\mathrm{Ph}, \mathrm{BiPh}$ and TerPh on $\mathrm{Au}(111)$. (b) Adsorption energies for DDT, Ph, BiPh, TerPh and mixed DDT:TerPh (1:1) SAMs on $\mathrm{Au}(111)$ and the contributions of intermolecular interactions and Au-S bond (binding).

\subsubsection{Impact of the side chain on the gold-sulfur interaction}

The Au-S bond strength (Figure 6b PBE-D3) is similar within the series of arylthiols studied (about $-2.10 \mathrm{eV}$ ), whereas for DDT it is equal to $-2.60 \mathrm{eV}$, thus suggesting that changes in the Au-S bond are dependent on the hybridisation of the R-C-S carbon atom. Nevertheless, as far as the series of thiols studied here is concerned, the differences in binding energy (max. $0.50 \mathrm{eV}$ ) are smaller than the contribution of the dispersion interactions (between -1.1 and - 
$1.94 \mathrm{eV}$ ), and thus can be considered to play only a secondary role in the differences in surface affinities of the various ligands.

\subsubsection{Intermolecular interactions: dispersion interactions between arylthiols}

The results and discussions above show that the Au-S bond and entropic effects are not the main origin of the differences in the exchange ability of arylthiols (Figure 5). Then, intermolecular interactions should be scrutinized. DFT calculations (Figure 6b) by taking into account dispersion forces show that attractive intermolecular interactions increase monotonously with the number of phenyl groups in the side chain, as expected from $\mathrm{C}-\mathrm{H} / \pi$ (for close to perpendicular phenyl groups in the T-shaped configuration) and $\pi / \pi$ ( $\pi$ stacking for parallel phenyl groups) interactions. ${ }^{[58,60]}$ Hence, as observed on planar self-assembled monolayers (SAMs), ${ }^{[61]}$ intermolecular interactions between aromatic groups stabilize the final SAM on the surface of the nanoparticles and are accounted for the exchange ability order between arylthiols: $R_{P h}<R_{B i P h}<R_{T e r P h}$.

\subsection{Role of the ligand functionality on the exchange: insights in the dodecanethiol/arylthiols system by DFT calculations}

At low concentration, $R_{P h}<R_{B i P h}<R_{T e r P h}<1$, so that DDT exchange by arylthiol is disfavored (surface empoverished in arylthiols). Entropy and intermolecular interactions may again play a role, as discussed below.

\subsubsection{Entropy balance in the DDT/arylthiol system}

As detailed above, configurational and conformational entropies of the final mixed SAM are higher than the initial DDT SAM and should favor the exchange. Likewise, the entropy balance clearly favors the exchange when a flexible molecule like DDT is released in a good solvent as chloroform, and replaced in the SAM by a rigid ligand like TerPh, which does not 
experience significant entropy loss upon grafting. Both considerations are in opposition to experimental results in the low concentration suspensions and show that entropy is, again, not the main drive of the exchange.

\subsubsection{Intermolecular interactions: the role of dispersion interactions between aliphatic} chains in the alkylthiol DDT SAM Calculations (Figure 6b) show that the total adsorption energy is higher for DDT than for TerPh because of increased intermolecular interactions. The same holds true for the pure DDT SAM versus the mixed DDT/TerPh SAM (Figure 6b). Dispersion interactions are indeed predominant in a compact fully-ordered SAM of long chain alkythiol molecules like DDT. ${ }^{[38,62,63]}$ The adsorption energy order is $\Delta E_{\text {ads }}(\mathrm{DDT})>\Delta E_{\mathrm{ads}}(\mathrm{TerPh})$ (absolute values) (Figure 6b). Even by considering a mixed SAM (DDT/TerPh) resulting from the exchange and eventual DDT-TerPh interactions at boundaries (Figures $\mathbf{6 b}$ and S8) of potential ligand domains within the mixed SAM, the initial pure DDT SAM is the most stable. This result is in agreement with measured $R_{T e r P h}<1$ for the diluted suspension (Figure 5) and shows again the predominant role of dispersion interactions in exchanges at play in the DDT/arylthiol system.

\subsection{Concentration effect on the exchange: insights in the dodecanethiol/arylthiols system}

For a concentrated suspension and contrary to the low concentration system (Figure 5a), $R_{T e r P h}>1$ on $5 \mathrm{~nm}$ nanoparticles, so that DFT calculations do not agree with the experimental observation. According to DFT calculations, fully exchanged and partially exchanged SAMs are close in energy, so that the enthalpy of the final SAM should not change significantly with the composition of the shell. ${ }^{[44]}$ Two other origins may then arise for the increase in $R_{T e r P h}$ with the concentration: (i) increase in the entropy and stability of the final SAM compared to low concentration; (ii) destabilization of TerPh initially in solution. The first case would be related to changes in the distribution of the ligands in the mixed SAMs upon a change in the 
concentration. This cause can be ruled out based on previous reports that always show similar stripy or patchy, relatively homogeneous, distributions of ligands on $5 \mathrm{~nm}$ nanoparticles. ${ }^{[15-}$ ${ }^{17,19,41-43]}$ The second case relates to the solubility of TerPh in chloroform, which may be close to the high concentration investigated ([particle $\left.]=10^{-4} \mathrm{M}\right)$ and displace equation (3) towards TerPh binding. This conclusion is supported by the qualitative observation of difficulties to solubilize TerPh in the concentrated system, which requires e.g. sonication, in opposition to all other ligands studied in the present work. Furthermore, the solvation layer surrounding the bound ligand shell may also impact surface energies and then relative stabilities of the mixed SAMs. Because of their similar length, DDT and TerPh should yield similar solvation layers, so that surface energies may not drive the exchange of DDT with TerPh. ${ }^{[14]}$ For the other arylthiols, as explained above, relatively homogeneous distributions of ligands are expected on $5 \mathrm{~nm}$ nanoparticles for all ligands, ${ }^{[15-17,19,41-43]}$ so that surface energies of the ligand shell should be similar and should not account for the differences in partition ratios for the various ligands. Through solubility effects, the DDT/TerPh system exemplifies how the exchange ability scale developed herein (Figure 5b) applies for a given solvent, here chloroform.

\subsection{Curvature effect: insights in the dodecanethiol/arylthiols system}

The influence of the nanoparticles size, in other words the surface curvature, was assessed for $5 \mathrm{~nm}$ and $2 \mathrm{~nm}$ nanoparticles (Figure 7) obtained with ligands exchange in a concentrated ([particle] $\left.=10^{-4} \mathrm{M}\right)$ system. $R_{\text {TerPh }}$ of 3.5 with $5 \mathrm{~nm}$ diameter decreases to 1.9 with $2 \mathrm{~nm}$ diameter. DDT exchange by $\mathrm{TerPh}$ is then more efficient on bigger nanoparticles. Several effects may contribute to such enhancement. First, the entropy gain from DDT release upon exchange should be maximized for bigger nanoparticles on which the DDT SAM is expected to be more packed in the outer part of the shell and more organized (lower entropy of the initial SAM). Second, the stability of the final mixed SAM should be increased on bigger 
$5 \mathrm{~nm}$ nanoparticles through entropic and enthalpic (intermolecular interactions) effects.

Indeed, an increase in the nanoparticle size may be accompanied by a change from Janus or patchy surface distribution to a more homogeneous organization of the ligands at the surface. ${ }^{[15-17,19,41-43]}$ This evolution is accompanied by configurational and conformational entropic stabilization of the mixed SAM. Besides, for rigid thiols, the decrease in curvature on big particles brings closer the end groups of neighboring molecules. In the case of TerPh ligands, the distance between the aromatic end groups decreases from $1.2 \mathrm{~nm}$ to $0.8 \mathrm{~nm}$ for 2 and $5 \mathrm{~nm}$ nanoparticles, respectively. Accordingly, phenyl-phenyl interactions are maximized on bigger nanoparticles. This "end-proximity" effect of the particle size may be less pronounced in the initial DDT SAMs, as DDT molecules should be sufficiently flexible to allow conformational changes in the outer shell to increase inter-chain interactions on both small and big particles.
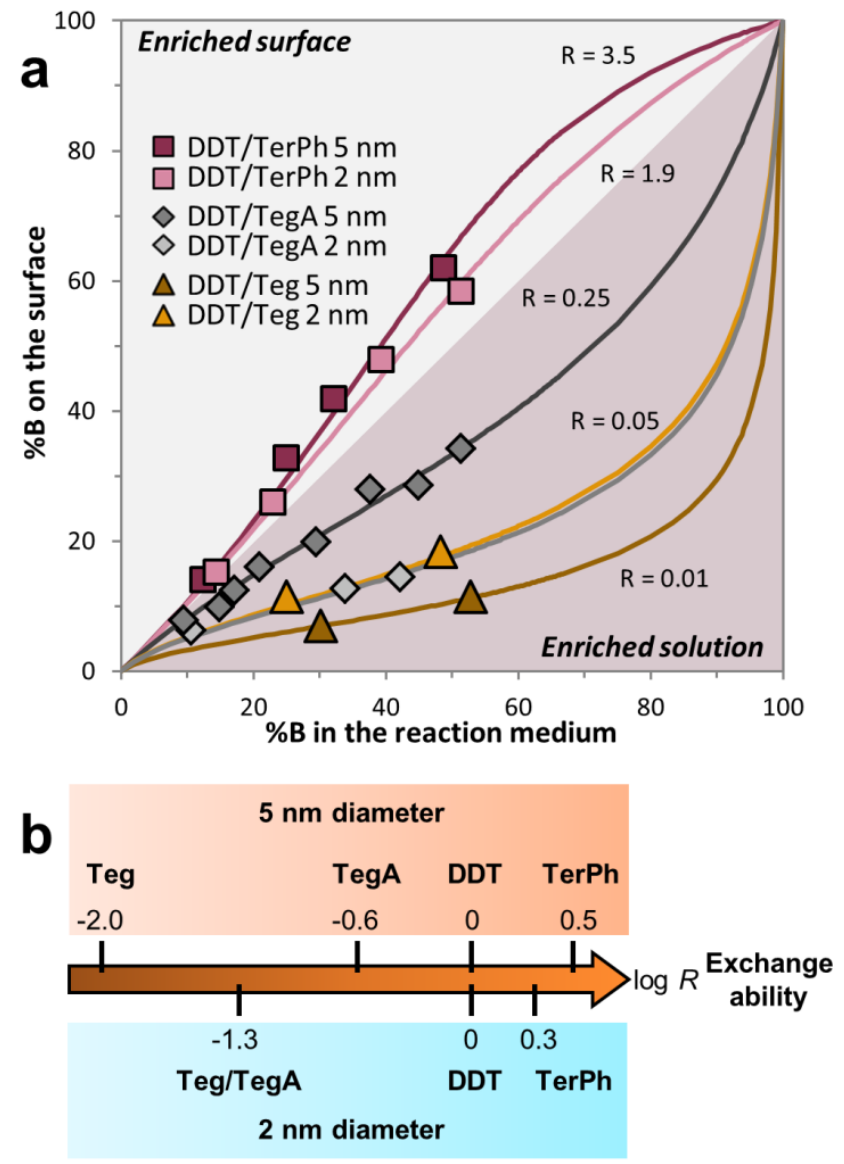
Figure 7. (a) Partition of $\mathrm{B}$ ligands (TerPh, TegA and Teg) for [particles] $10^{-4} \mathrm{M}$. Partition ratios $R$ are given for each DDT/B couple of ligands. (b) Exchange ability scale for TerPh, TegA and Teg versus DDT at a nanoparticles concentration of ca. $10^{-4} \mathrm{M}$ in $\mathrm{CDCl}_{3}$.

\subsection{Extended range of ligand functionality by ligands exchange}

DDT Exchange experiments have been extended beyond arylthiols to other ligands TegA and Teg (Figures 2 and 7): in concentrated suspensions of $5 \mathrm{~nm}$ nanoparticles, $R_{\text {TerPh }}>R_{\text {TegA }}>$ $R_{\text {Teg. }}$ In the absence of DFT calculations, only brief, qualitative and speculative considerations are presented below to discuss this exchange efficiency order.

Calculations described above (Figure 6) show that the Au-S bond energy is poorly sensitive to strongly conjugated systems. Then, we speculate that the Au-S bond energy is independent on the TegA and Teg substituents and should not modify the exchange ability.

Based on previous reports, ${ }^{[15-17,19,41-43]}$ one can assume on $5 \mathrm{~nm}$ nanoparticles relatively homogeneous (small patches or stripes, not Janus particles) distributions in the mixed SAMs for all ligands, so that mixing entropy is expected similar for the DDT/TerPh, DDT/TegA and DDT/Teg SAMs. As for TerPh, Teg molecules have a length similar to DDT, while TegA is longer than DDT. The gain in conformational entropy during the exchange is then negligible for Teg but may be large for TegA. The gain in entropy during exchange due to DDT release in the solution accompanying grafting of an incoming ligand is expected lower for TegA and Teg that have rigidity similar to DDT, than for more rigid TerPh molecules. In brief, entropic effects are expected to favor exchange of DDT with TegA rather than Teg.

Teg and TegA ethylene glycol units do not form ordered domains ${ }^{[64]}$ because of the competition between dispersion forces, directional interactions between $\mathrm{C}-\mathrm{O}$ dipoles, and steric repulsion between chains. ${ }^{[65]}$ In the patchy or stripy distributions expected in mixed SAMs on $5 \mathrm{~nm}$ nanoparticles, ${ }^{[15-17,19,41-43]}$ TegA molecules can interact together by H-bonds between the amide groups within a SAM, as already demonstrated. ${ }^{[66-68]}$ Therefore, enthalpic 
stabilization is expected higher for the final mixed SAMs containing TegA rather than Teg.

All in all, both entropic and enthalpic effects favor DDT exchange by TegA rather than by Teg, in agreement with experiment results (Figure 7).

The nanoparticles size again influences the exchange (Figure 7). Indeed, as for TerPh, exchange by TegA is favored for larger particles. This may again be related (i) to the entropy gain during DDT release from a SAM denser on bigger particles, (ii) to entropic stabilization of the mixed SAM due to a change in the distribution of the ligands, and (iii) to H-bonds more prone to form in a denser SAM on bigger particles. On the contrary, exchange by Teg is disfavored on big particles. Because of similar size and stiffness of the DDT and Teg molecules, entropy gain from solubilized molecules during exchange could be neglected as well as entropic stabilization of the mixed SAM due to a change in the ligands distribution as the particle size decreases. Thus, a speculative explanation may rely on enthalpic effects: as explained above, incorporating Teg molecules should disturb the densely packed DDT SAM and result in a loss of stabilizing DDT/DDT interactions. Obviously, the discussion drawn in this section requires confirmation by further calculations, out of the scope of this work.

\subsection{Effect of the functionalization method on the surface composition}

Finally, NMR titrations have been performed on suspensions of nanoparticles synthesized directly in the presence of ligands couples DDT/TegA and DDT/Teg (bi-ligands syntheses) (Figure 8). This method was applied to nanoparticles synthesized through Brust-Schiffrin's and Stucky's protocols in a large range of ligands ratio. Polydispersity varies upon an increase in the proportion of the incoming ligand B (Figures S8-S10). For the DDT/Teg couple, surface compositions are similar to those measured for ligands exchange (Figure 4). For DDT/TegA, the bi-ligands synthesis leads to a different outcome: the surface is enriched in TegA compared to the synthesis medium, contrary to ligands exchange. Further investigations 
are required to decipher the different origins of such behaviours (solvation and kinetic effects for instance).

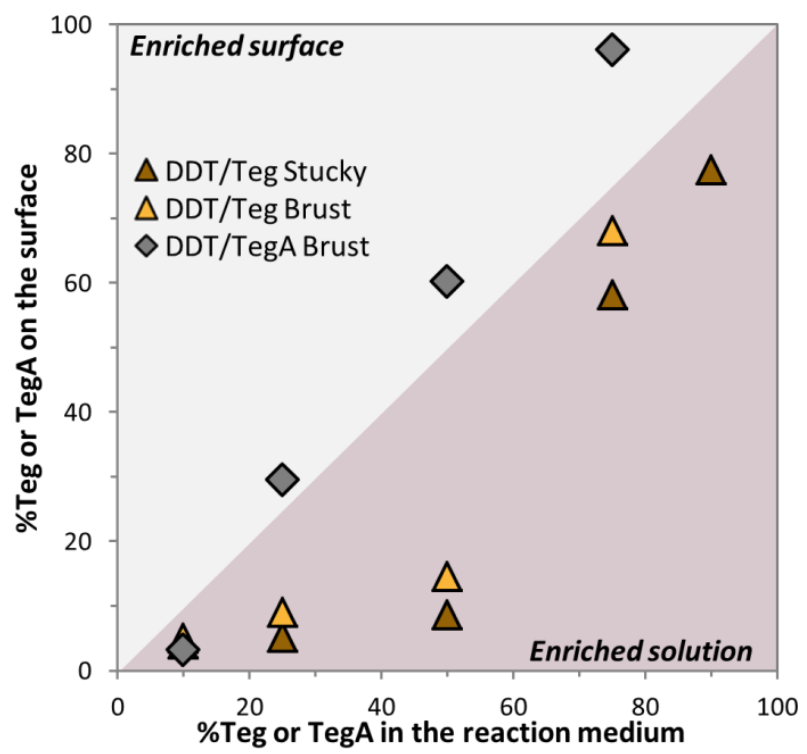

Figure 8. Surface composition versus reaction medium composition for bi-ligands synthesis with different ligands couples and synthesis protocols.

\section{Conclusion}

The formation of bi-ligands self-assembled monolayers on gold metal nanoparticles has been monitored by liquid state ${ }^{1} \mathrm{H}$ NMR spectroscopy. The approach allows studying the time evolution of the ligand shell during ligands exchange, up to the steady-state, where compositions of the ligand monolayer and the surrounding medium can be quantified after ligands exchange. The resulting molecular partition can be used to build scales of exchange ability for a given initial SAM (an alkylthiol is used herein as a reference) and a specific solvent. Such scales may be used as tools to select the right experimental conditions to target specific surface compositions. 
More important, placing different ligands on these scales enables identifying the role of ligands functionality, concentration and particle size on the exchange. These data shed a new light on the parameters driving the composition of ligand shells: besides the grafting group, the end-group and the chain length, which have already been studied, ${ }^{[38,39]}$ the nature of the chain also has a large impact on the exchange and the final SAM composition. This approach has been used on the specific case of arylthiol series with the support of DFT calculations. Hence, the role of entropic and intermolecular forces has been deciphered. We have demonstrated that for arylthiols in diluted suspensions, intermolecular forces are the main driving force of the exchange and the origin for the exchange ability varying among the ligand series.

Our experimental results suggest that similar considerations may apply also to other syntheses of multi-functional nanoparticles, such as bi-ligands synthesis, and to other ligands, containing polyethylene oxide moieties that are relevant for biological applications. ${ }^{[69-71]}$ In these cases, entropy may play a stronger role, both related to the stability of the final SAM through the surface distribution of the ligands in the mixed SAM, ${ }^{[14,16,17,19,41-43]}$ and to the entropy balance during ligands exchange. Besides, in this article, the reaction pathway for ligand exchange has not been examined. In the future, further calculations may unravel such dynamical effects.

Finally, the methodology developed herein on gold nanoparticles and thiol ligands may be applicable to other kinds of non-magnetic particles, such as metals and chalcogenides ${ }^{[37]}$, provided that the ligands can be fully detached from the inorganic core, for instance with cyanide ${ }^{[25]}$ or aqua regia. ${ }^{[72]}$ The results reported in this study thus pave the way to a rational design of hybrid nano-systems with quantified multifunctionalities.

\section{Experimental and method section}


All reagents were purchased from Sigma-Aldrich and used as received. Details of ligands synthesis, characterization and DFT calculations are given in SI.

Nanoparticle syntheses: $5 \mathrm{~nm}$ gold nanoparticles were synthesized using a method described by Stucky et coll. ${ }^{[7]}$ Briefly, $\mathrm{AuCl}(\mathrm{PPh})_{3}(300 \mathrm{mg}, 1$ eq.) was dissolved in $60 \mathrm{~mL}$ of toluene with $1.16 \mathrm{~mL}$ of dodecanethiol (DDT, 8 eq.). The solution was stirred at $100{ }^{\circ} \mathrm{C}$ for $5 \mathrm{~min}$ and a preheated solution containing $526 \mathrm{mg}$ (10 eq.) of tert-butylamine borane complex in $36 \mathrm{~mL}$ of toluene was added. The mixture was stirred at $100{ }^{\circ} \mathrm{C}$ for $3 \mathrm{~min}$ and cooled down to room temperature. The gold nanoparticles were precipitated with ethanol and separated from the reaction medium by centrifugation, the supernatant was removed and 4 cycles of redispersion in toluene $(1 \mathrm{~mL})$, precipitation with ethanol $(20 \mathrm{~mL})$ and centrifugation were achieved. Then, the particles were dispersed in $80 \mathrm{~mL}$ of toluene, the suspension was divided into $5 \mathrm{~mL}$ batches and dried under vacuum.

$2 \mathrm{~nm}$ gold nanoparticles were synthesized using Brust-Schiffrin's method. ${ }^{[5]} 100 \mathrm{mg}$ (1.0 eq.) of $\mathrm{HAuCl}_{4} \cdot 3 \mathrm{H}_{2} \mathrm{O}$ was dissolved in $7.5 \mathrm{~mL}$ of water and transferred in toluene with a solution of $308 \mathrm{mg}$ of tetraoctylammonium bromide (2.2 eq.) in $5.7 \mathrm{~mL}$ of toluene. The aqueous layer was removed and a solution of $51.4 \mathrm{mg}(1.0$ eq. $)$ of DDT in $1.75 \mathrm{~mL}$ of toluene was added. The mixture was stirred and cooled at $0{ }^{\circ} \mathrm{C}$ and $7 \mathrm{~mL}$ of a cold $\mathrm{NaBH}_{4}$ aqueous solution $(0.36 \mathrm{M}, 10.0$ eq. $)$ was added quickly under vigorous stirring. After 3 hours at room temperature, the aqueous layer was removed, the organic layer was washed with water, and the particles were precipitated with ethanol and recovered by centrifugation. The washing procedure and fractionation into batches is the same as for the $5 \mathrm{~nm}$ particles. Quantitative yields were verified by adding some strong reductant $\mathrm{NaBH}_{4}$ to the colorless supernatants after the first centrifugation. The supernatants remained colorless, thus showing that all gold precursors had reacted. 
Bi-ligands syntheses: The Brust-Schiffrin's protocol remained the same as described above but DDT was replaced with a mixture of two ligands. Stucky's method for DDT/Teg couple was performed in chloroform at $60^{\circ} \mathrm{C}$ for 25 minutes. For each sample, the washing procedure was modified according to the dispersion ability of the particles. For both methods, the bi-ligands nanoparticles were around $3 \mathrm{~nm}$ in diameter (see supplementary information SI). Quantitative yields were verified by the procedure described above.

Ligands exchange kinetics: The exchange was performed at $25{ }^{\circ} \mathrm{C}$. A batch of DDT-stabilized gold nanoparticles was dispersed in a NMR tube using $\mathrm{CDCl}_{3}$ to obtain a fresh and stable colloidal dispersion. The ${ }^{1} \mathrm{H}$ spectrum was acquired. Then, a given quantity of the second ligand was added in a small volume of $\mathrm{CDCl}_{3}$. The mixture was vigorously stirred outside the spectrometer before measurement and its ${ }^{1} \mathrm{H}$ spectrum was monitored regularly until it doesn't change anymore. Every ligands exchange was followed through specific signals, which were deconvoluted if required, e.g. for the DDT/TegA couple. In some cases, little oxidation of the thiols into disulfides occurred. Disulfides can be easily identified by ${ }^{1} \mathrm{H}$ NMR. With TegA and Teg, a small proportion of disulfides $(5-10 \%$ mol.) was already present when adding the ligands in the NMR tubes. This quantity sometimes increased but the conversion of thiols into disulfides occurred after the stabilization of the ligands shell's composition. Accordingly, disulfides were considered not being involved in ligand exchange, in agreement with previous works which have shown that disulfides are much less active than the corresponding thiols in exchange reactions. ${ }^{[38]}$ To assess the effect of concentration, ligands exchange experiments were run with $\mathrm{TerPh}, \mathrm{BiPh}$ and $\mathrm{Ph}$ ligands with suspensions initially diluted $\sim 300$ times. Once the steady state was reached, as evidenced by stable UV-visible spectra, ${ }^{[15]}$ the suspensions were concentrated by evaporation in ca. $30 \mathrm{~min}$, the particles were washed with ethanol 3 times to get rid of the free ligands, dried under vacuum and transferred into NMR tubes with $\mathrm{CDCl}_{3}$ in order to record their ${ }^{1} \mathrm{H}$ NMR spectra and check for the absence of free ligands. The 
composition of the ligands shell was then determined by ${ }^{1} \mathrm{H}$ NMR with the iodine death reaction. $^{[54]}$

Determination of the medium and shell compositions for bi-ligands syntheses: ${ }^{1} \mathrm{H}$ NMR was again used to assess the composition of the ligand shell after nanoparticles separation and redispersion in $\mathrm{CDCl}_{3}$. A ${ }^{1} \mathrm{H}$ spectrum was first acquired to quantify the possible remaining free species, then the iodine death reaction ${ }^{[54]}$ was conducted to oxidize all the thiols and recover them as free disulfides in the reaction medium, to be titrated by ${ }^{1} \mathrm{H}$ NMR.

\section{Supporting Information}

Supporting Information is available from the Wiley Online Library or from the author: Synthesis procedures for the different ligands, details of the calculation level, Figures S1-S11, Schemes S1-S2.

\section{Acknowledgements}

This work was funded by the C'Nano Ile de France DIM Nano-K under the project NaJaH. L.P. and P.Q. thank the support given by Santa Fe Science Technology and Innovation Agency (ASACTEI, grant 00010-18-2014), CONICET and PICT-2014-1084.

Received: ((will be filled in by the editorial staff))

Revised: ((will be filled in by the editorial staff)) Published online: ((will be filled in by the editorial staff))

References

[1] K. Saha, S. S. Agasti, C. Kim, X. Li, V. M. Rotello, Chem. Rev. 2012, 112, 2739-2779.

[2] L. Dykman, N. Khlebtsov, Chem. Soc. Rev. 2012, 41, 2256-82.

[3] E. C. Dreaden, A. M. Alkilany, X. Huang, C. J. Murphy, M. a El-Sayed, Chem. Soc. Rev. 2012, 41, 2740-79.

[4] M. Montalti, L. Prodi, N. Zaccheroni, R. Baxter, G. Teobaldi, F. Zerbetto, Langmuir 2003, 19, 5172-5174.

[5] M. Brust, M. Walker, D. Bethell, D. J. Schiffrin, R. Whyman, J. Chem. Soc. Chem. Commun. 1994, 801-802.

[6] H. Hiramatsu, Chem. Mater. 2004, 16, 2509-2511.

[7] N. Zheng, J. Fan, G. D. Stucky, J. Am. Chem. Soc. 2006, 128, 6550-6551. 
[8] E. Boisselier, L. Salmon, J. Ruiz, D. Astruc, Chem. Commun. 2008, 5788-90.

[9] B. C. Mei, K. Susumu, I. L. Medintz, J. B. Delehanty, T. J. Mountziaris, H. Mattoussi, J. Mater. Chem. 2008, 18, 4949-4958.

[10] A. Verma, O. Uzun, Y. Hu, Y. Hu, H.-S. Han, N. Watson, S. Chen, D. J. Irvine, F. Stellacci, Nat. Mater. 2008, 7, 588-95.

[11] C. Vilain, F. Goettmann, A. Moores, P. Le Floch, C. Sanchez, J. Mater. Chem. 2007, 17,3509 .

[12] A. Ghosh, S. Basak, B. H. Wunsch, R. Kumar, F. Stellacci, Angew. Chem. Int. Ed. Engl. 2011, 50, 7900-5.

[13] D. Nykypanchuk, M. M. Maye, D. van der Lelie, O. Gang, Nature 2008, 451, 549-552.

[14] A. M. Jackson, J. W. Myerson, F. Stellacci, Nat. Mater. 2004, 3, 330-6.

[15] C. Goldmann, R. Lazzari, X. Paquez, C. Boissière, F. Ribot, C. Sanchez, C. Chanéac, D. Portehault, ACS Nano 2015, 9, 7572-7582.

[16] Q. K. Ong, J. Reguera, P. J. Silva, M. Moglianetti, K. Harkness, M. Longobardi, K. S. Mali, C. Renner, S. De Feyter, F. Stellacci, ACS Nano 2013, 7, 8529-8539.

[17] M. Moglianetti, Q. K. Ong, J. Reguera, K. M. Harkness, M. Mameli, A. Radulescu, J. Kohlbrecher, C. Jud, D. I. Svergun, F. Stellacci, Chem. Sci. 2014, 5, 1232-1240.

[18] S. Carenco, X. F. Le Goff, J. Shi, L. Roiban, O. Ersen, C. Boissière, C. Sanchez, N. Mézailles, Chem. Mater. 2011, 23, 2270-2277.

[19] C. Singh, P. Ghorai, M. Horsch, A. Jackson, R. Larson, F. Stellacci, S. Glotzer, Phys. Rev. Lett. 2007, 99, 226106.

[20] K. M. Harkness, B. C. Hixson, L. S. Fenn, B. N. Turner, A. C. Rape, C. a Simpson, B. J. Huffman, T. C. Okoli, J. a McLean, D. E. Cliffel, Anal. Chem. 2010, 82, 9268-74.

[21] A. P. Gies, D. M. Hercules, A. E. Gerdon, D. E. Cliffel, JACS 2007, 129, 1095-1104.

[22] P. Ionita, A. Caragheorgheopol, B. C. Gilbert, V. Chechik, J. Am. Chem. Soc. 2002, 124, 9048-9049. 
[23] L. Maus, J. P. Spatz, R. Fiammengo, Langmuir 2009, 25, 7910-7917.

[24] A. Stewart, S. Zheng, M. R. McCourt, S. E. J. Bell, ACS Nano 2012, 6, 3718-3726.

[25] X. Liu, M. Yu, H. Kim, M. Mameli, F. Stellacci, Nat. Commun. 2012, 3, 1182.

[26] L. Pasquato, M. Sologan, C. Cantarutti, S. Bidoggia, S. Polizzi, P. Pengo, Faraday Discuss. 2016, 191, 527-543.

[27] I. Moreels, B. Fritzinger, J. C. Martins, Z. Hens, J. Am. Chem. Soc. 2008, 130, 1508115086.

[28] A. M. Smith, L. E. Marbella, K. a. Johnston, M. J. Hartmann, S. E. Crawford, L. M. Kozycz, D. S. Seferos, J. E. Millstone, Anal. Chem. 2015, 87, 2771-2778.

[29] L. E. Marbella, J. E. Millstone, Chem. Mater. 2015, 27, 2721-2739.

[30] G. Guarino, F. Rastrelli, F. Mancin, Chem. Commun. 2012, 48, 1523.

[31] G. Guarino, F. Rastrelli, P. Scrimin, F. Mancin, J. Am. Chem. Soc. 2012, 134, 72007203.

[32] M. Şologan, D. Marson, S. Polizzi, P. Pengo, S. Boccardo, S. Pricl, P. Posocco, L. Pasquato, ACS Nano 2016, 10, 9316-9325.

[33] I. Moreels, Y. Justo, B. De Geyter, K. Haustraete, J. C. Martins, Z. Hens, ACS Nano 2012, 5, 2004-2012.

[34] R. Sharma, G. P. Holland, V. C. Solomon, H. Zimmermann, S. Schiffenhaus, S. a. Amin, D. a Buttry, J. L. Yarger, J. Phys. Chem. C 2009, 113, 16387-16393.

[35] R. L. Donkers, Y. Song, R. W. Murray, Langmuir 2004, 20, 4703-4707.

[36] R. Guo, Y. Song, G. Wang, R. W. Murray, J. Am. Chem. Soc. 2005, 127, 2752-2757.

[37] R. R. Knauf, J. C. Lennox, J. L. Dempsey, Chem. Mater. 2016, DOI 10.1021/acs.chemmater.6b01827.

[38] M. J. Hostetler, A. C. Templeton, R. W. Murray, C. Hill, N. Carolina, Langmuir 1999, 15, 3782-3789.

[39] P. Ionita, A. Caragheorgheopol, B. C. Gilbert, V. Chechik, J. Am. Chem. Soc. 2002, 
[40] K. Heister, D. L. Allara, K. Bahnck, S. Frey, M. Zharnikov, M. Grunze, Langmuir $1999,15,5440-5443$.

[41] P. K. Ghorai, S. C. Glotzer, J. Phys. Chem. C 2010, 114, 19182-19187.

[42] X. Liu, M. Yu, H. Kim, M. Mameli, F. Stellacci, Nat. Commun. 2012, 3, 1182.

[43] H. Kim, R. P. Carney, J. Reguera, Q. K. Ong, X. Liu, F. Stellacci, Adv. Mater. 2012, $1-7$.

[44] X. Ge, P. C. Ke, T. P. Davis, F. Ding, Small 2015, 11, 4894-4899.

[45] C. D. Bain, G. M. Whitesides, 1988, 6560-6561.

[46] F. Tielens, V. Humblot, C. M. Pradier, M. Calatayud, F. Illas, Langmuir 2009, 25, $9980-9985$.

[47] I. C. Pons-Siepermann, S. C. Glotzer, ACS Nano 2012, 6, 3919-3924.

[48] Z. Huang, C. Lu, B. Dong, G. Xu, C. Ji, K. Zhao, L.-T. Yan, Nanoscale 2016, 8, $1024-1032$.

[49] J. J. Kuna, K. Voïtchovsky, C. Singh, H. Jiang, S. Mwenifumbo, P. K. Ghorai, M. M. Stevens, S. C. Glotzer, F. Stellacci, Nat. Mater. 2009, 8, 837-42.

[50] A. Badia, L. Demers, L. Dickinson, F. G. Morin, R. B. Lennox, L. Reven, J. Am. Chem. Soc. 1997, 119, 11104-11105.

[51] Z. Hens, J. C. Martins, Chem. Mater. 2013, 25, 1211-1221.

[52] F. Ribot, V. Escax, C. Roiland, C. Sanchez, J. C. Martins, M. Biesemans, I. Verbruggen, R. Willem, Chem. Commun. 2005, 1019-1021.

[53] O. Kohlmann, W. E. Steinmetz, X. Mao, W. P. Wuelfing, A. C. Templeton, R. W. Murray, C. S. Johnson, J. Phys. Chem. B 2001, 105, 8801-8809.

[54] A. C. Templeton, M. J. Hostetler, C. T. Kraft, R. W. Murray, J. Am. Chem. Soc. 1998, 120, 1906-1911.

[55] H. Hinterwirth, S. Kappel, T. Waitz, T. Prohaska, W. Lindner, M. Lämmerhofer, ACS 
Nano 2013, 7, 1129-1136.

[56] A. Bashir, W. Azzam, M. Rohwerder, A. Terfort, Langmuir 2013, 29, 13449-13456.

[57] V. V. Korolkov, S. Allen, C. J. Roberts, S. J. B. Tendler, J. Phys. Chem. C 2011, 115, 14899-14906.

[58] X. Wu, M. C. Vargas, S. Nayak, V. Lotrich, G. Scoles, J. Chem. Phys. 2001, 115, $8748-8757$.

[59] D. Costa, C.-M. Pradier, F. Tielens, L. Savio, Surf. Sci. Rep. 2015, 70, 449-553.

[60] M. Alonso, T. Woller, F. J. Martín-Martínez, J. Contreras-García, P. Geerlings, F. De Proft, Chem. - A Eur. J. 2014, 20, 4931-4941.

[61] E. Sabatani, J. C. Cohen-Boulakia, M. Bruening, I. Rubinstein, Langmuir 1993, 9, 2974-2981.

[62] W. J. Miller, N. L. Abbott, Langmuir 1997, 13, 7106-7114.

[63] C. Vericat, M. E. Vela, G. Benitez, P. Carro, R. C. Salvarezza, Chem. Soc. Rev. 2010, 39, 1805-1834.

[64] P. Harder, M. Grunze, R. Dahint, D. Heidelberg, J. Phys. Chem. B 1998, 5647102, $426-436$.

[65] R. a. Boto, J. Contreras-García, M. Calatayud, Comput. Theor. Chem. 2015, 1053, $322-327$.

[66] A. K. Boal, V. M. Rotello, Langmuir 2000, 16, 9527-9532.

[67] R. S. Clegg, J. E. Hutchison, J. Am. Chem. Soc. 1999, 20, 5319-5327.

[68] P. M. Donaldson, P. Hamm, Angew. Chemie - Int. Ed. 2013, 52, 634-638.

[69] A. G. Kanaras, F. S. Kamounah, K. Schaumburg, C. J. Kiely, M. Brust, Chem. Commun. 2002, 2294-2295.

[70] T. A. Larson, P. P. Joshi, K. Sokolov, ACS Nano 2012, 6, 9182-9190.

[71] F. Schulz, T. Vossmeyer, N. G. Bastús, H. Weller, Langmuir 2013, 29, 9897-9908.

[72] J. J. Buckley, E. Couderc, M. J. Greaney, J. Munteanu, C. T. Riche, S. E. Bradforth, R. 
L. Brutchey, ACS Nano 2014, 8, 2512-2521. 
Quantitative assessment by NMR of the surface composition of gold nanoparticles capped by competing thiol ligands unravels the relationship between the compositions of the ligand shell and the reaction medium. The combination with DFT calculations unveils the role of intermolecular forces and entropy on the stability of mixed ligand shells, towards further control of multifunctionality in hybrid nanoparticles.

Gold nanoparticles,

Multifunctional nanoparticles,

Ligand exchange,

Nuclear Magnetic Resonance,

Density Functional Theory

C. Goldmann, F. Ribot, L. F. Peiretti, P. Quaino, F. Tielens, C. Sanchez, C. Chanéac, D.

Portehault

Quantified Binding Scale of Competing Ligands at the Surface of Gold Nanoparticles: the Role of Entropy and Intermolecular Forces

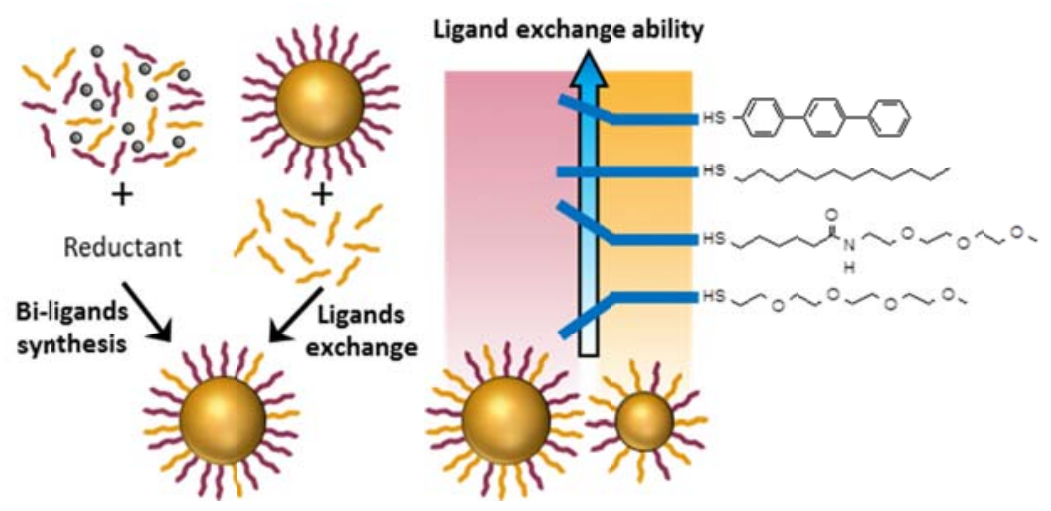


Copyright WILEY-VCH Verlag GmbH \& Co. KGaA, 69469 Weinheim, Germany, 2016.

\section{Supporting Information}

\section{Quantified Binding Scale of Competing Ligands at the Surface of Gold Nanoparticles: the Role of Entropy and Intermolecular Forces}

Claire Goldmann, ${ }^{a}$ François Ribot,${ }^{a}$ Leonardo F. Peiretti, ${ }^{b}$ Paola Quaino, ${ }^{b}$ Frederik Tielens, ${ }^{a}$ Clément Sanchez, ${ }^{a}$ Corinne Chanéac, ${ }^{a}$ and David Portehault ${ }^{a, *}$

Dr. C. Goldmann, Dr. F. Ribot, Dr. F. Tielens, Prof. C. Sanchez, Dr. C. Chanéac, Dr. D. Portehault

Sorbonne Universités, UPMC Univ Paris 06, CNRS, Collège de France, Laboratoire de Chimie de la Matière Condensée de Paris (CMCP), 11 place Marcelin Berthelot, F-75005, Paris, France

E-mail: david.portehault@upmc.fr

Dr. L. F. Peiretti, Dr. P. Quaino

Preline, Facultad de Ingeniería Química, Universidad Nacional del Litoral, 3000, Santa Fe, Argentina

\section{Table of content}

\section{Methods}

Figure S1. Full NMR spectra acquired during DDT/TerPh exchange

Figure S2. TEM pictures for DDT/TerPh exchanges $(2 \mathrm{~nm})$

Figure S3. Evolution of the free and bonded species during DDT/Teg and DDT/TegA exchanges $(2 \mathrm{~nm})$

Figure S4. TEM pictures and size distributions for DDT/TerPh exchanges $(5 \mathrm{~nm})$

Figure S5. TEM pictures and size distributions for DDT/TegA exchanges $(5 \mathrm{~nm})$

Figure S6. TEM pictures and size distributions for DDT/Teg exchanges $(5 \mathrm{~nm})$

\section{Computational details}

Figure S7. Model of the DDT SAM for calculation of the adsorption energy

Figure S8. Model of the mixed DDT:TerPh SAM for calculation of the adsorption energy

Figure S9. TEM pictures of DDT/TegA Brust bi-ligands synthesis

Figure S10. TEM pictures of DDT/Teg Brust bi-ligands synthesis

Figure S11. TEM pictures of DDT/TegA Brust bi-ligands synthesis

Scheme S1. Synthesis of Teg ligand

Scheme S2. Synthesis of TegA ligand

Evaluation of the uncertainty of NMR titration 
Ligands syntheses. 1-mercapto-3,6-9,12-tetraoxotridecane (Teg) was synthesized from a reported procedure.[E. E. Foos, A. W. Snow, M. E. Twigg, M. G. Ancona, 2002, 2401-2408] The first step was modified using another method that gave a better yield.[K. W. and T. H. Mikio Ouchi, Yoshihisa Inoue, Yu Liu, Satoshi Nagamune, Satoko Nakamura, Bull. Chem. Soc. Jpn. 1990, 63, 1260-1262] N-\{2-[2-(2-methoxyethoxy)ethoxy]ethyl $\}-6-$ sulfanylhexanamide (TegA) was synthesized using the method reported by Pengo et al.[P. Pengo, S. Polizzi, M. Battagliarin, L. Pasquato, P. Scrimin, J. Mater. Chem. 2003, 13, 2471] Peptide coupling for TegA was performed using the protocol described by Kleinert et al.[M. Kleinert, T. Winkler, A. Terfort, T. K. Lindhorst, Org. Biomol. Chem. 2008, 6, 2118-2132]

Iodine death reaction.[A. C. Templeton, M. J. Hostetler, C. T. Kraft, R. W. Murray, J. Am. Chem. Soc. 1998, 120, 1906-1911] All free and bonded thiols were oxidized into free disulfides by adding a small quantity of iodine crystals directly into the NMR tube. Iodine oxidizes the free and bonded thiols into disulfides, triggering desorption from the surface: every ligands in the reaction medium then become free species and their amounts can be determined by integration of the ${ }^{1} \mathrm{H}$ NMR and comparison with calibrated solutions. The grafting density was evaluated by normalizing the amount of bonded species versus the gold surface area according to the particles size measured by transmission electron microscopy on at least 500 nanoparticles. Note that a similar procedure by replacing iodine with potassium cyanide was unsuccessful to dissolve the gold cores because of the too low solubility of $\mathrm{KCN}$ in $\mathrm{CDCl}_{3}$.

NMR spectroscopy. ${ }^{1} \mathrm{H}$ NMR was performed at a temperature of $25{ }^{\circ} \mathrm{C} \pm 0.1{ }^{\circ} \mathrm{C}$ on a Bruker Avance $^{\text {III }} 300$ spectrometer $\left(300.13 \mathrm{MHz}\right.$ for $\left.{ }^{1} \mathrm{H}\right)$ equipped with a $5 \mathrm{~mm}$ BBFO probe. A $30^{\circ}$ pulse was used with an acquisition time of $1.95 \mathrm{~s}$ and a recycling delay of $7.4 \mathrm{~s}$. These values were large enough to allow total relaxation. 64 scans were summed for each spectrum. The following parameters (standard conditions) were used for data recording: LOCK / ATMA (tuning of the probe) / Shim of the probe; signal processing: $\mathrm{SI}=32 \mathrm{~K} / \mathrm{LB}=0.3 \mathrm{~Hz} / \mathrm{EF} /$ phasing / ABS (baseline correction).

Transmission electron microscopy. TEM observations were performed on a Tecnai Spirit $\mathrm{G} 2$ microscope operating at $120 \mathrm{kV}$. The nanoparticles were deposited onto carbon-coated copper grids from diluted chloroform suspensions and then dried in air.

DFT model. The T-shaped adatom configuration (Figure 5 and details in the SIComputational details) used for arylthiol SAMs is in agreement with previous STM observations on flat Au(111) surfaces.[ A. Bashir, W. Azzam, M. Rohwerder, A. Terfort, Langmuir 2013, 29, 13449-13456] In contrast with alkyl chain thiol SAMs, the arylthiols yield "corrugated" patterns with phenyl groups of neighboring molecules parallel or nearly perpendicular to each other (Figure 5). The thiols are bonded in pairs on a gold adatom on a $(2 \sqrt{3} \times 2 \sqrt{3}) \mathrm{Au}(111)$ surface. The formation of adatoms is in line with our recent study predicting this reconstruction for thiols interacting strongly with the $\mathrm{Au}(111)$ surface.[E. Bedford, V. Humblot, C. Methivier, C.-M. Pradier, F. Gu, F. Tielens, S. Boujday, Chem. - A Eur. J. 2015, 21, 14555-14561] Details of the calculation level are given in SI.

Calculation of the different contributions to the adsorption energy. The adsorption energy $\Delta E_{\text {ads }}$ is the adsorption energy of one thiol ${ }_{\mathrm{A}}$ chain in a perfectly ordered SAM:

$\Delta E_{\mathrm{ads}}=\Delta E_{\mathrm{ads}, \mathrm{PBE}}+\Delta E_{\mathrm{disp}}$

with $\Delta E_{\text {ads,PBE }}$ the adsorption energy calculated from the pure DFT-PBE[J. P. Perdew, K. Burke, M. Ernzerhof, Phys. Rev. Lett. 1996, 77, 3865-3868; J. P. Perdew, K. Burke, M. 
Ernzerhof, Phys. Rev. Lett. 1997, 78, 1396-1396] electron energies, hence not taking into account dispersion interactions. $\Delta E_{\text {disp }}$ is the dispersion interaction energy. Both quantities are evaluated according to the following equation:

$\Delta E_{\text {ads,PBE }}=1 / 4\left[E\left(\right.\right.$ thiol $\left.\left._{\mathrm{A}} / \mathrm{Au}(111)\right)-4 . E\left(\operatorname{thiol}_{\mathrm{A}}\right)-E(\mathrm{Au}(111))\right]$

where $E\left(\right.$ thiol $\left._{\mathrm{A}} / \mathrm{Au}(111)\right), E\left(\operatorname{thiol}_{\mathrm{A}}\right)$, and $E(\mathrm{Au}(111))$ are the total electronic energies at the DFT-PBE level of the adsorption complex formed by thiol $\mathrm{A}_{\mathrm{A}}$, the isolated thiol $\mathrm{A}_{\mathrm{A}}$ under its radical form, and the $\mathrm{Au}(111)$ slab, obtained after separate geometry optimization, respectively. $\Delta E_{\text {disp }}$ was calculated by means of the DFT-D3 approach[X. Wu, M. C. Vargas, S. Nayak, V. Lotrich, G. Scoles, J. Chem. Phys. 2001, 115, 8748-8757; S. Grimme, J. Antony, S. Ehrlich, H. Krieg, J. Chem. Phys. 2010, 132, 154104] by using a semi-empirical dispersion potential.

The Au-S binding energy $\Delta E_{\text {bind-(S-Au) }}$ was calculated as follows:

$\Delta E_{\text {bind(S-Au) }}=1 / 4\left[E\left(\right.\right.$ thiol $\left._{\mathrm{A}} / \mathrm{Au}(111)\right)-E\left(4\right.$ thiol $\left.\left._{\mathrm{A}}\right)-E(\mathrm{Au}(111))\right]$

where $E\left(\right.$ thiol $\left._{\mathrm{A}} / \mathrm{Au}(111)\right)$ and $E(\mathrm{Au}(111))$ are the total electronic energies at the PBE level of the whole system and the bare surface, respectively. Whereas $E\left(4 t_{i o l}\right)$ is the electronic energy at the same level of theory of the 4 isolated thiolates in their radical form without the presence of the substrate.

From equation (1), the inter-chain interaction energy $\Delta E_{\text {int.chain }}$ can be retrieved. For the sake of comparison, adsorption energies were calculated with and without considering dispersion interactions, at the DFT-PBE-D3 $\left(\Delta E_{\text {ads,PBE }}+\Delta E_{\text {disp }}\right)$ and the DFT-PBE $\left(\Delta E_{\text {ads,PBE }}\right)$ levels of calculation, respectively. 


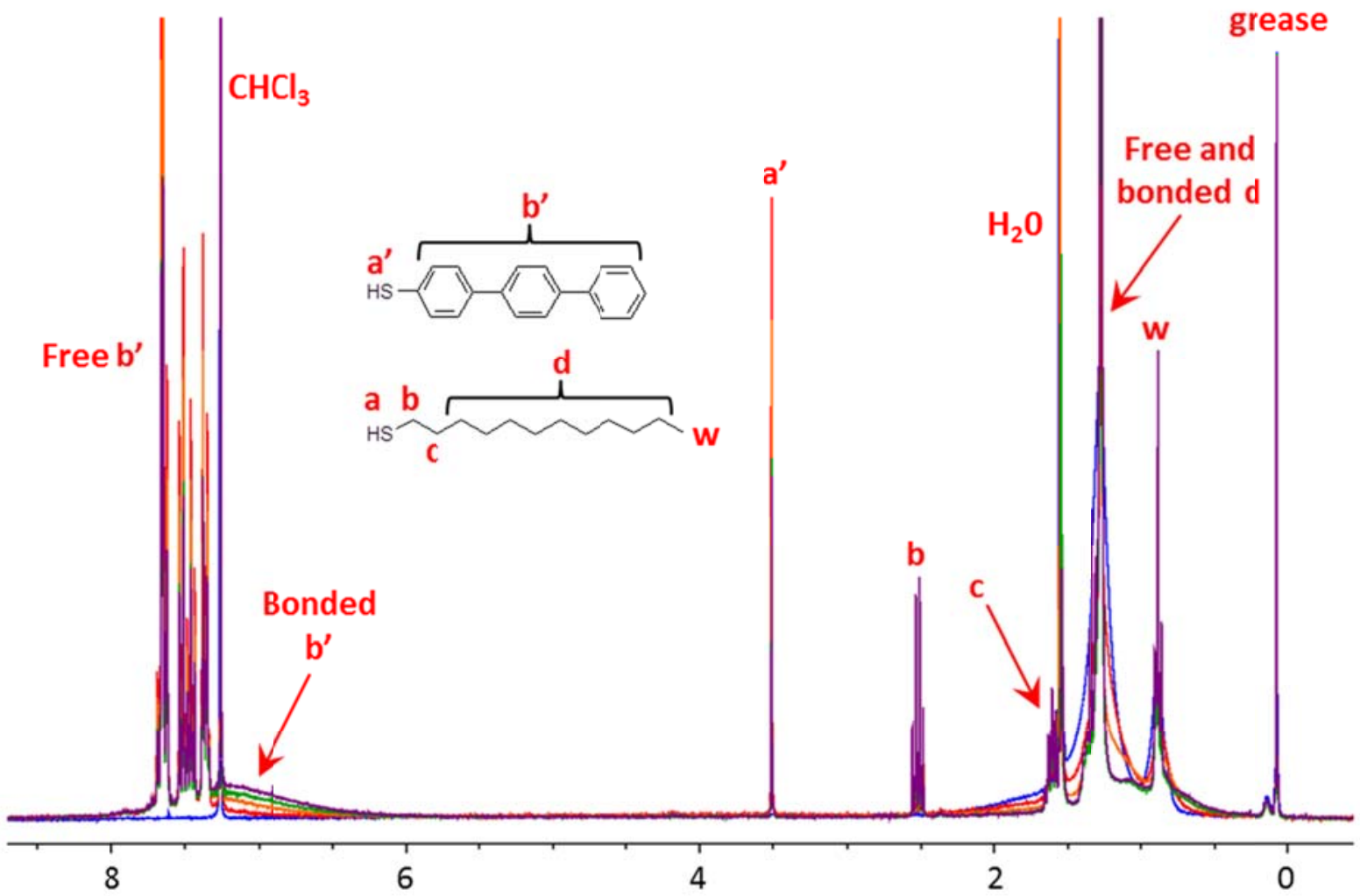

Figure S1. Overall NMR spectra acquired during exchange between DDT and TerPh on $2 \mathrm{~nm}$ nanoparticles in $\mathrm{CDCl}_{3}$. Colors correspond to different reaction durations: initial state before TerPh addition (blue), $\mathrm{t}=10 \min (\mathrm{red}), \mathrm{t}=3 \mathrm{~h}$ (orange), $\mathrm{t}=34 \mathrm{~h}$ (green) and $\mathrm{t}=110 \mathrm{~h}$ (purple). 


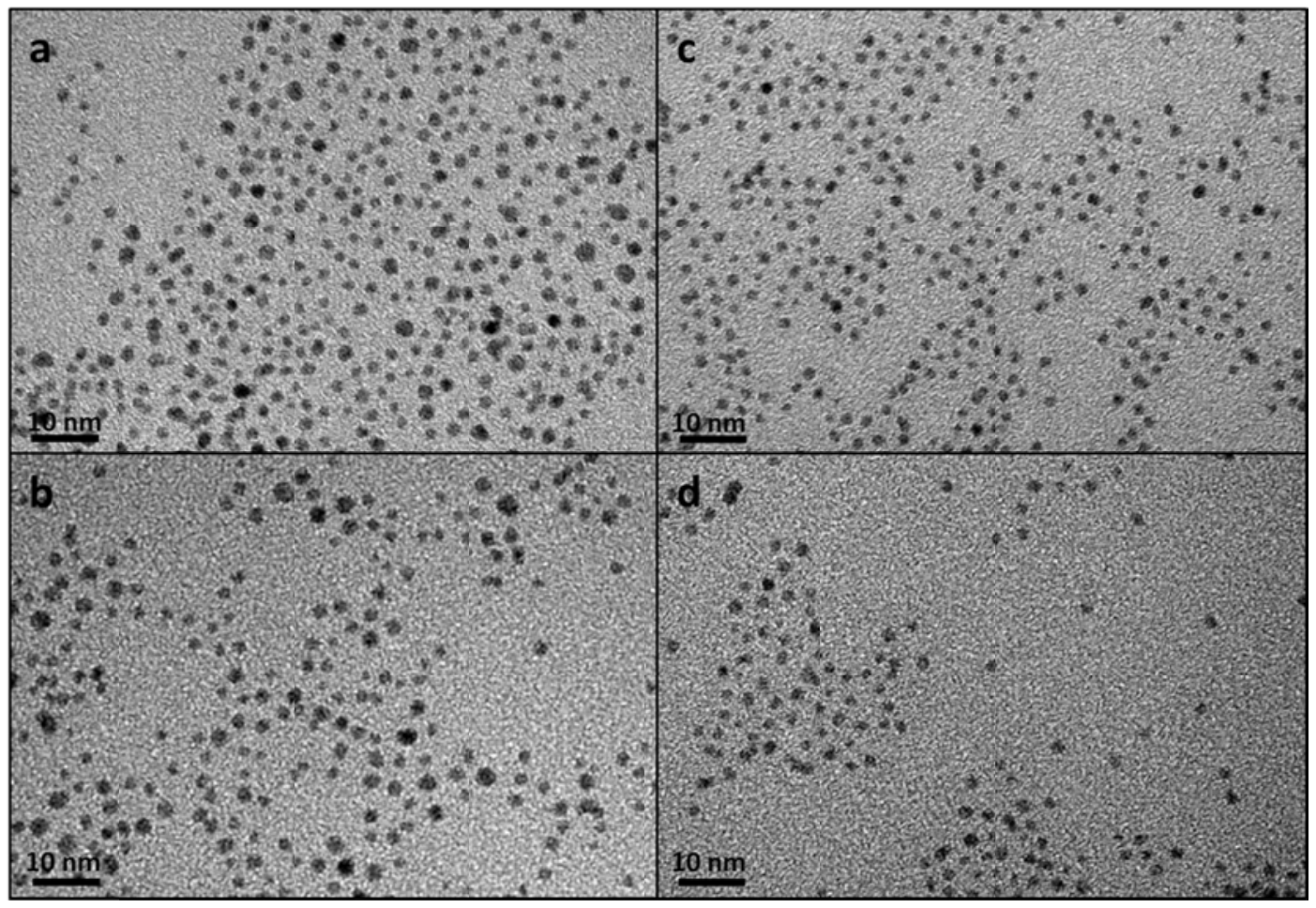

Figure S2. (a) and( b) TEM pictures of $2 \mathrm{~nm}$ nanoparticles covered with DDT before ligand exchange. (c) and (d) Same sample after ligand exchange $(110 \mathrm{~h})$ with TerPh and with a final surface composition of DDT:TerPh 48:52.
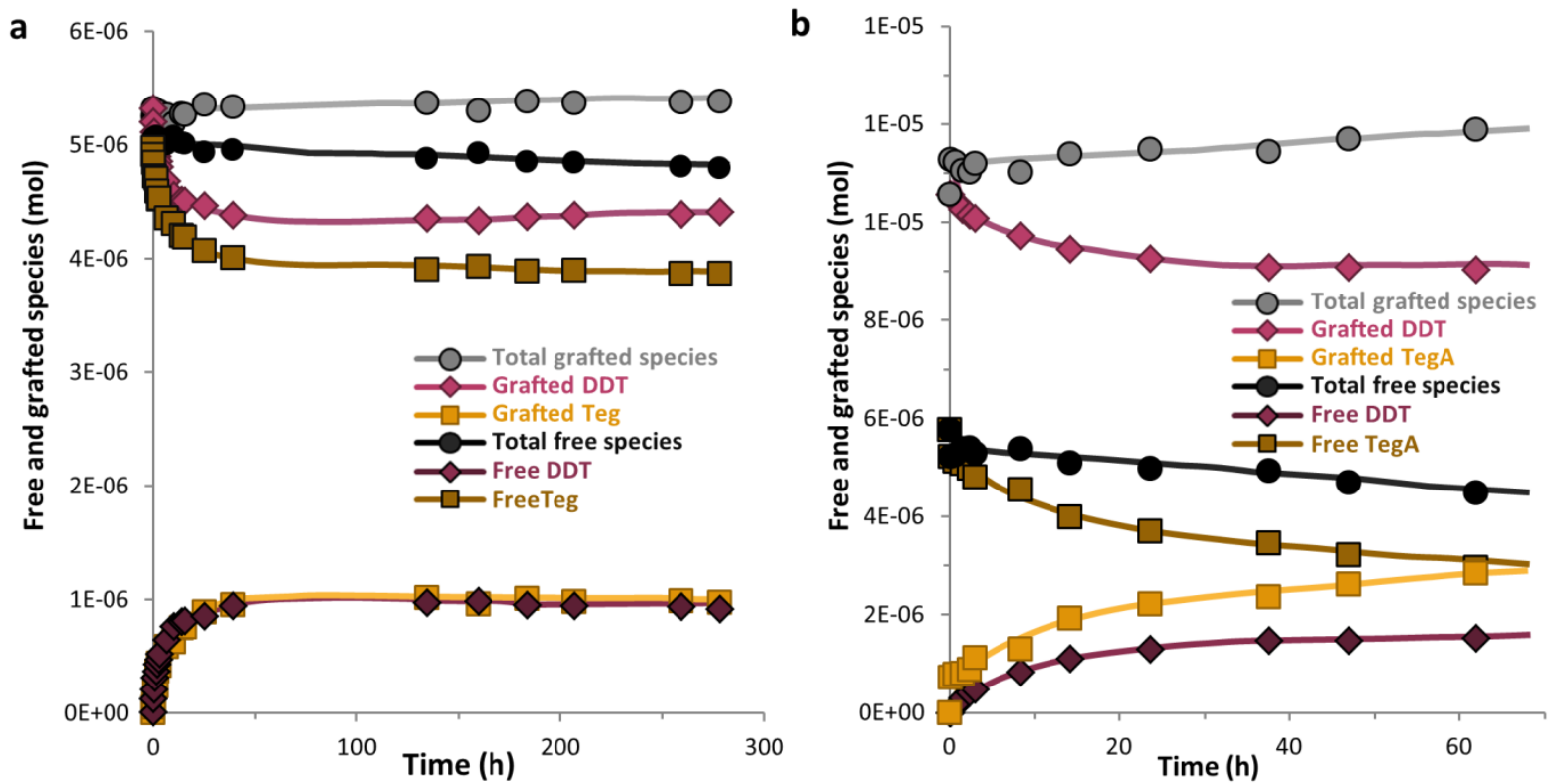

Figure S3. Time evolution of the amounts of each species in solution and on the surface at a nanoparticle concentration of $1.10^{-4} \mathrm{M}(\mathrm{d}=2 \mathrm{~nm})$. (a) DDT/Teg exchange with $\%$ Teg $\mathrm{g}_{\text {medium }}=$ 48\%. (b) DDT/TegA exchange with $\% \mathrm{TegA}_{\text {medium }}=42 \%$. 


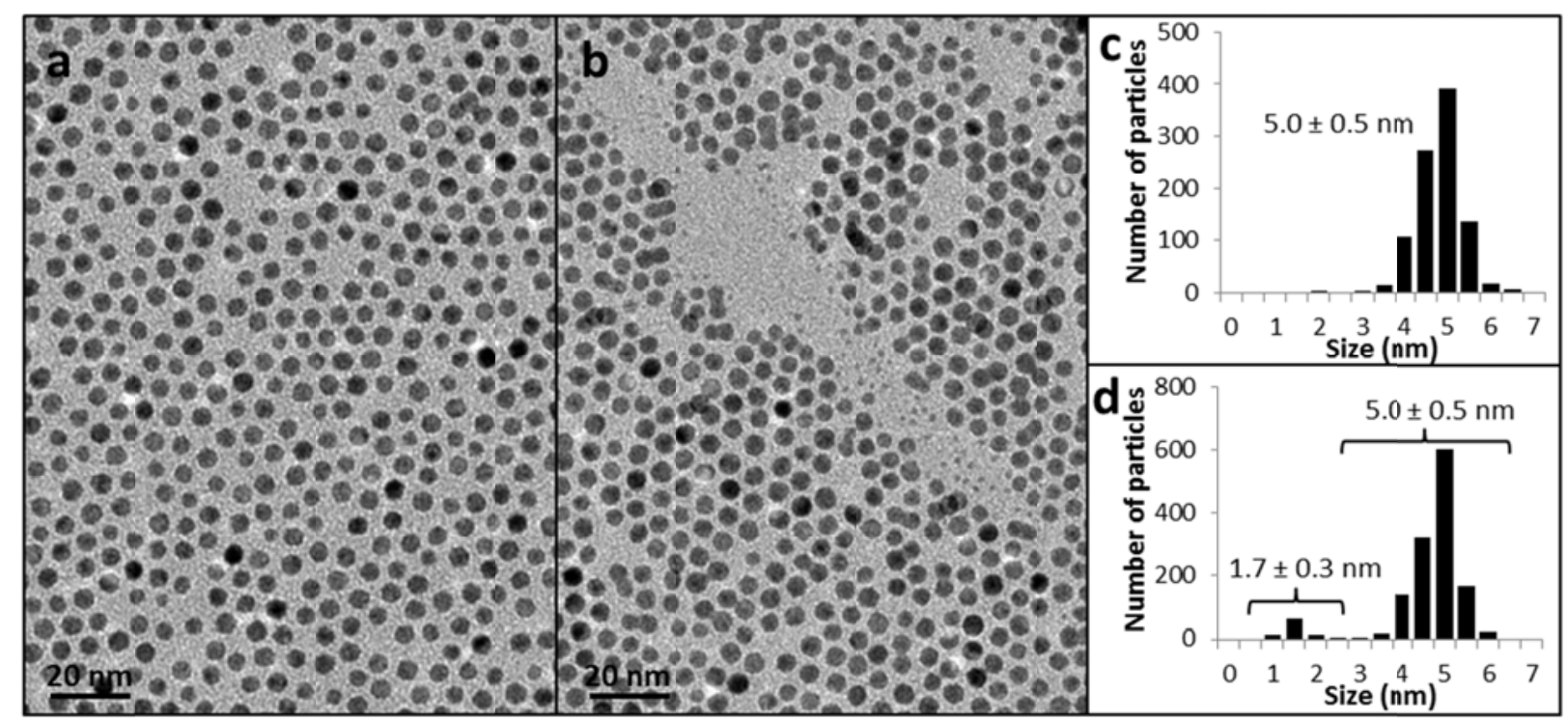

Figure S6. TEM pictures of a suspension of $5 \mathrm{~nm}$ gold nanoparticles before (a) and after (b) the exchange of DDT by Teg $(72 \mathrm{~h})$. At the end of the ligand exchange, the DDT:Teg proportion is 98:2 on the surface. Size distribution of the particles before (c) and after exchange (d). 


\section{Computational Details}

\section{Calculation level}

All calculations were performed using the $a b$ initio plane-wave pseudopotential approach as implemented in the VASP code ${ }^{1,2}$.

The Perdew-Burke-Ernzerhof (PBE) functional (refs 63 and 64 of the main text) was chosen to perform the periodic DFT calculations with an accuracy on the overall convergence tested elsewhere ${ }^{3,4,5,6,7,8}$.

The valence electrons were treated explicitly and their interactions with the ionic cores are described by the Projector Augmented-Wave method (PAW) ${ }^{2,9,10}$. This allows using a low energy cut off equal to $400 \mathrm{eV}$ for the plane-wave basis. The integration over the Brillouin zone was performed on the $\Gamma$-point, in all calculations.

In the geometry optimizations at $0 \mathrm{~K}$, the positions of all atoms in the supercell are relaxed in the potential energy determined by the full quantum mechanical electronic structure until the total energy differences between the loops is less than $10^{-4} \mathrm{eV}$.

In order to account for the dispersion interaction in the SAM system, the DFT-D3 approach of Grimme (ref 64 in the main text) was used, as implemented in VASP, which consists in adding a semi-empirical dispersion potential to the conventional Kohn-Sham DFT energy.

\section{Description of the DDT SAM model}

Experimentally, the DDT SAM on $\mathrm{Au}(111)$ forms an ordered $(\sqrt{3} \times \sqrt{3}) \mathrm{R} 30^{\circ}$ type lattice containing both gas phase and liquid environments. (Ref 53 in the main text) The alkanethiolate molecules are chemisorbed on the Au surface by their S-tails forming a thiolate bond and a tilt angle of about $35^{\circ}$ with respect to the substrate normal, which is also recovered from the calculations. The adsorption site is taken to be on the displaced bridge site ${ }^{11}$. The calculations were carried out without considering any possible drastic reconstruction of the gold surface, such as the formation of gold adatoms. We have chosen to simulate the surface with a $(\sqrt{ } 3 \times 2 \sqrt{ } 3) R 30^{\circ}$ unit cell containing two thiol molecules. This choice emerges from a

\footnotetext{
${ }^{1}$ Kresse, G.; Furthmuller, J. Efficient Iterative Schemes for Ab Initio Total-Energy Calculations Using a PlaneWave Basis Set. Physical Review B 1996, 54, 11169-11186.

${ }^{2}$ Kresse, G.; Joubert, D. From Ultrasoft Pseudopotentials to the Projector Augmented-Wave Method. Physical Review B 1999, 59, 1758-1775.

${ }^{3}$ Tielens, F.; Gervais, C.; Lambert, J. F.; Mauri, F.; Costa, D. Ab Initio Study of the Hydroxylated Surface of Amorphous Silica: A Representative Model. Chemistry of Materials 2008, 20, 3336-3344.

${ }^{4}$ Calatayud, M.; Tielens, F.; De Proft, F. Reactivity of Gas-Phase, Crystal and Supported $\mathrm{V}_{2} \mathrm{O}_{5}$ Systems Studied Using Density Functional Theory Based Reactivity Indices. Chemical Physics Letters 2008, 456, 59-63.

${ }^{5}$ de Bocarme, T. V.; Chau, T. D.; Tielens, F.; Andres, J.; Gaspard, P.; Wang, R. L. C.; Kreuzer, H. J.; Kruse, N. Oxygen Adsorption on Gold Nanofacets and Model Clusters. Journal of Chemical Physics 2006, 125.

${ }^{6}$ Tielens, F.; Andres, J.; Chau, T. D.; de Bocarme, T. V.; Kruse, N.; Geerlings, P. Molecular Oxygen Adsorption on Electropositive Nano Gold Tips. Chemical Physics Letters 2006, 421, 433-438.

${ }^{7}$ Tielens, F.; Calatayud, M.; Dzwigaj, S.; Che, M. What Do Vanadium Framework Sites Look Like in Redox Model Silicate Zeolites? Microporous and Mesoporous Materials 2009, 119, 137-143.

${ }^{8}$ Tielens, F.; Trejda, M.; Ziolek, M.; Dzwigaj, S. Nature of Vanadium Species in V Substituted Zeolites: A Combined Experimental and Theoretical Study. Catalysis Today 2008, 139, 221-226

${ }^{9}$ Blochl, P. E.; Jepsen, O.; Andersen, O. K. Improved Tetrahedron Method for Brillouin-Zone Integrations. Physical Review B 1994, 49, 16223-16233.

${ }^{10}$ Blochl, P. E. Projector Augmented-Wave Method. Physical Review B 1994, 50, 17953-17979.

${ }^{11}$ Luque, N. B.; Santos, E.; Andres, J.; Tielens, F. Effect of Coverage and Defects on the Adsorption of Propanethiol on $\mathrm{Au}(111)$ Surface: A Theoretical Study. Langmuir 2011, 27, 14514-14521
} 
price/quality point of view. The surface layer was modeled by a minimal slab consisting of 5 hexagonal layers with 6 atoms each.
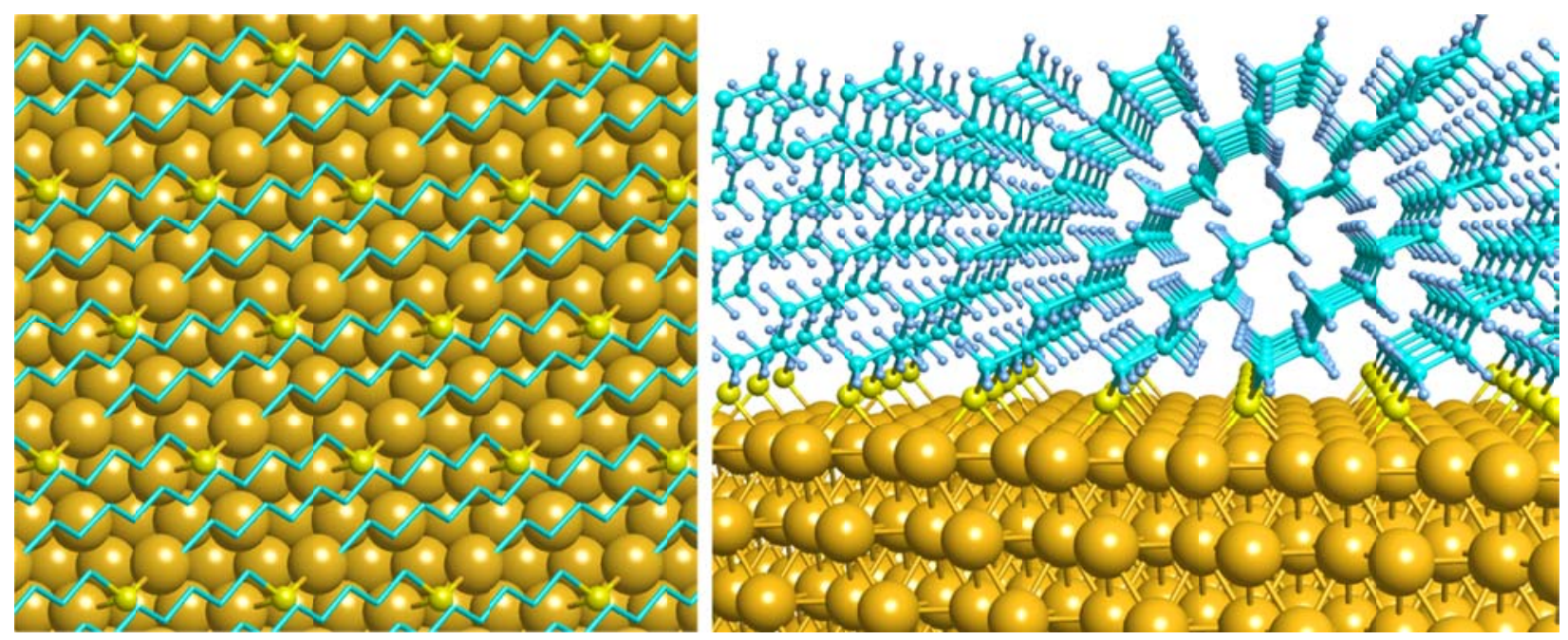

Figure S7. Model of the DDT SAM for calculation of the adsorption energy.

\section{Description of the mixed DDT:TerPh SAM model.}

The mixed DDT:TerPh SAM model was modeled using the same used unit cell $\left((2 \sqrt{3} \times \sqrt{3}) \mathrm{R} 30^{\circ}\right)$ containing two thiols, with the same number of $\mathrm{Au}$ atom layers as used for the pure TerPh SAMs. The adsorption site was chosen to be the hollow site on the Au(111) surface following the structure of the TerPh chains. Indeed, the TerPh chains adsorb differently to the surface as compared with the alkyl chain thiols, i.e. straight vs. tilted and hollow vs. displaced bridge, respectively. So, a perfect 1:1 mixture was build following the geometrical characteristics of the TerPh SAM, as can be seen in Figure S8.
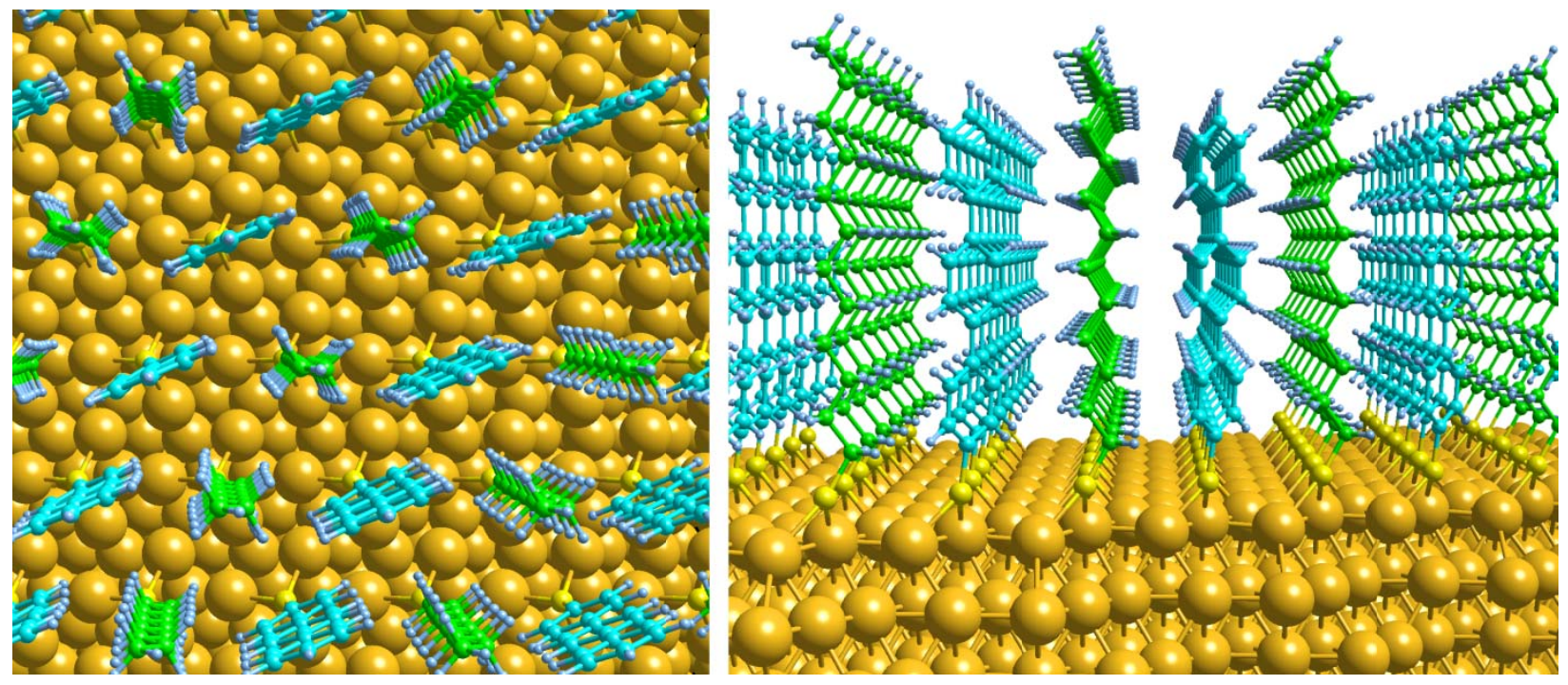

Figure S8. Model of the mixed DDT:TerPh SAM with a 1:1 ratio for calculation of the adsorption energy and intermolecular interactions in the mixed SAM. 
Scheme S1. Synthesis of the Teg ligand

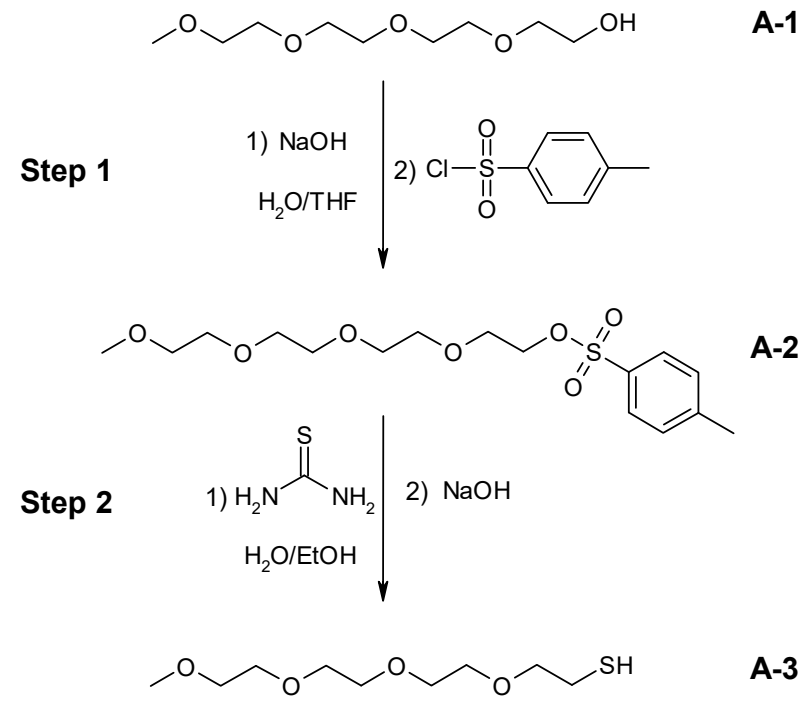

Step 1 (from Bull. Chem. Soc. Jpn, 1990, 63, 1260)

The commercial alcohol A-1 (2.00 g, 1.00 eq.) was dissolved in $2.8 \mathrm{~mL}$ of THF and $2.8 \mathrm{~mL}$ of a $\mathrm{NaOH}$ solution $\left(5 \mathrm{M}, 1.44\right.$ eq.) were added. The temperature of the mixture was set to $0^{\circ} \mathrm{C}$ under stirring and $2.8 \mathrm{~mL}$ of a solution of tosyle chloride (3.2 M, 0.93 eq.) were added slowly while the temperature was maintained between $0^{\circ} \mathrm{C}$ and $5^{\circ} \mathrm{C}$. At the end of the addition, the mixture was kept under stirring at $0^{\circ} \mathrm{C}$ for 3 hours. Cold water was added to the reaction medium and the product was extracted twice with $30 \mathrm{~mL}$ of dichloromethane. The organic layer was washed with water, dried on $\mathrm{MgSO}_{4}$, filtered and evaporated to give $2.85 \mathrm{~g}$ of a colorless liquid corresponding to the attempted product A-2. Yield $=88 \%$.

RMN ${ }^{1} \mathrm{H}(\mathrm{CDCl} 3,300 \mathrm{MHz}): 2.42$ (s, 3H, ArCH3), 3.35 (s, 3H, OCH3), 3.50-3.68 (m, 14H, OCH2), 4.13 (t, 2H, CH2OTs), 7.32 (d, 2H, Ar), 7.77 (d, 2H, Ar).

Step 2 (from Chem. Mater., 2002, 14, 2401)

The activated alcohol A-2 (2.00 g, 1.0 eq.) was dissolved in $3.55 \mathrm{~mL}$ of ethanol, $3.55 \mathrm{~mL}$ of a solution of thiourea (1.7 M, 1.1 éq.) were added and the mixture was refluxed for 4 hours. $3.55 \mathrm{~mL}$ of a $\mathrm{NaOH}$ solution $(1.7 \mathrm{M}, 1.1$ eq.) were then added and the mixture was again refluxed for 4 hours. The reaction medium was cooled at room temperature, the $\mathrm{pH}$ was adjusted to 3 thanks to concentrated $\mathrm{HCl} .10 \mathrm{~mL}$ of water were added to the mixture and the product was extracted with dichloromethane. The organic layer was washed with water, dried on $\mathrm{MgSO}_{4}$, filtered and evaporated to yield $1.21 \mathrm{~g}$ of a colorless liquid. The purification was achieved by chromatography on silica gel with dichloromethane. $0.93 \mathrm{~g}$ of product A-3 was obtained. Yield $=75 \%$.

RMN ${ }^{1} \mathrm{H}(\mathrm{CDCl} 3,300 \mathrm{MHz}): 1.56$ (t, 1H, SH), 2.66 (q, 2H, CH2S), 3.34 (s, 3H, CH3), 3.49$3.63(\mathrm{~m}, 14 \mathrm{H}, \mathrm{OCH} 2)$ 
Scheme S2. Synthesis of the TegA ligand

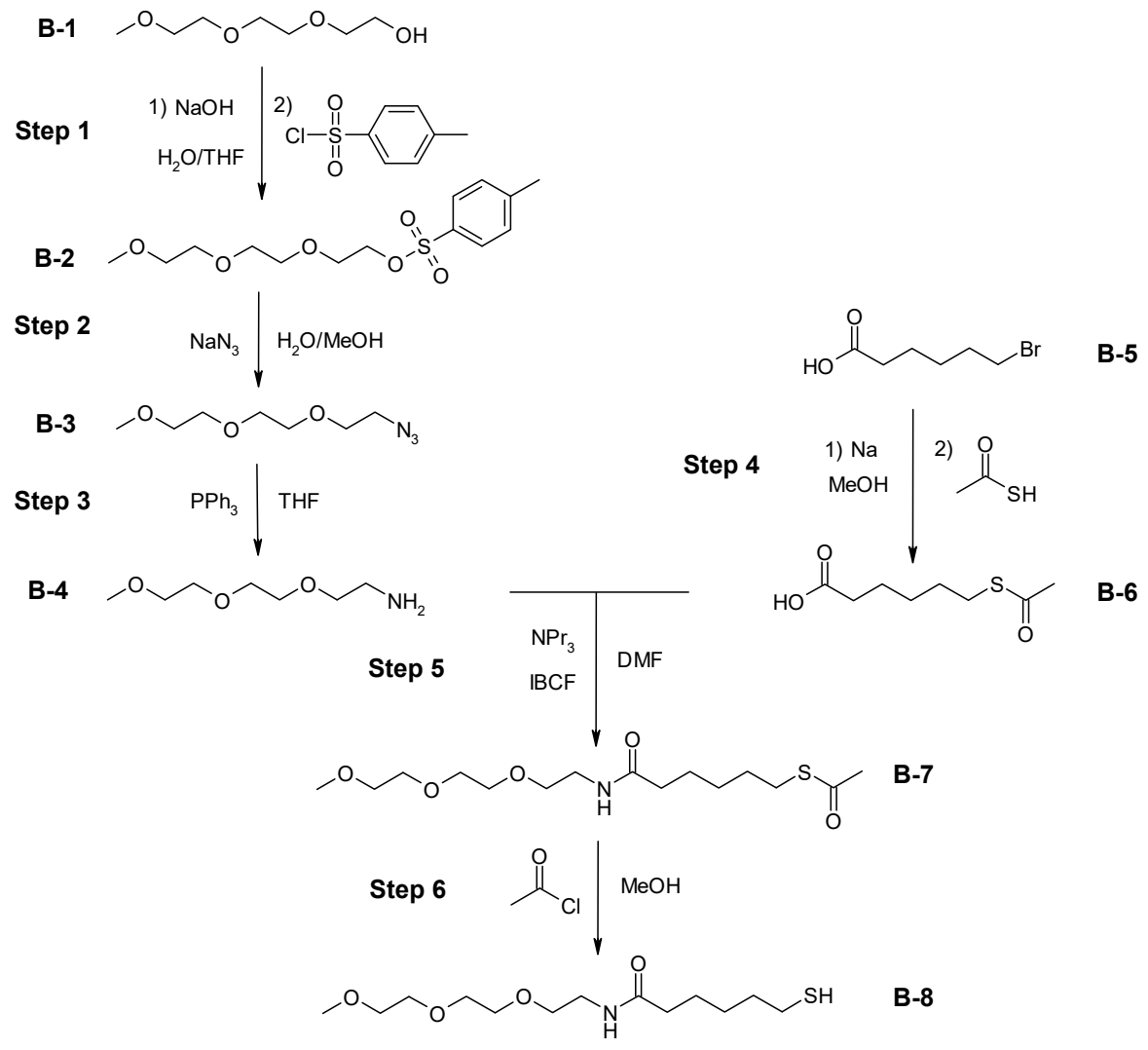

Step 1 (from J. Mater. Chem., 2003, 13, 2471)

The commercial alcohol B-1 (50.0 g, 1.0 eq.) was dissolved in $88 \mathrm{~mL}$ of THF and $88 \mathrm{~mL}$ of a $\mathrm{NaOH}$ solution $\left(5 \mathrm{M}, 1.44\right.$ eq.) were added. The temperature of the mixture was set to $0^{\circ} \mathrm{C}$ under stirring and $88 \mathrm{~mL}$ of a solution of tosyle chloride (3.2 M, 0.96 eq.) were added slowly while the temperature was maintained between $0^{\circ} \mathrm{C}$ and $5^{\circ} \mathrm{C}$. At the end of the addition, the mixture was kept under stirring at $0^{\circ} \mathrm{C}$ for 3 hours. Cold water was added to the reaction medium and the product was extracted twice with $30 \mathrm{~mL}$ of dichloromethane. The organic layer was washed with water, dried on $\mathrm{MgSO}_{4}$, filtered and evaporated to give $83.9 \mathrm{~g}$ of a colorless liquid corresponding to the attempted product B-2. Yield $=86 \%$.

RMN ${ }^{1} \mathrm{H}\left(\mathrm{CDCl}_{3}, 300 \mathrm{MHz}\right): 2.42$ (s, 3H, $\left.\mathrm{ArCH}_{3}\right), 3.35$ (s, 3H, $\left.\mathrm{OCH}_{3}\right), 3.48-3.68(\mathrm{~m}, 10 \mathrm{H}$, $\left.\mathrm{OCH}_{2}\right), 4.13$ (t, 2H, CH${ }_{2} \mathrm{OTs}$ ), 7.32 (d, 2H, Ar), 7.77 (d, 2H, Ar)

Step 2 (from J. Mater. Chem., 2003, 13, 2471)

The tosylate B-2 (15.0 g, 1.0 eq.) was put in a pyrex bottle and a solution of $\mathrm{NaN}_{3}$ was added (38.6 $\mathrm{g}$ in a mixture of $100 \mathrm{~mL}$ of water and $50 \mathrm{~mL}$ of methanol, $12.6 \mathrm{eq}$.). The bottle was sealed and the mixture was put in the oven at $75^{\circ} \mathrm{C}$ for 24 hours. The methanol was evaporated under vacuum and the product was extracted with dichloromethane. The organic layer was washed with water, dried on $\mathrm{MgSO}_{4}$, filtered and evaporated to give $7.6 \mathrm{~g}$ of a colorless liquid corresponding to the attempted product B-3. Yield $=85 \%$.

$\mathrm{RMN}{ }^{1} \mathrm{H}\left(\mathrm{CDCl}_{3}, 300 \mathrm{MHz}\right): 3.36\left(\mathrm{~m}, 5 \mathrm{H}, \mathrm{OCH}_{3}\right.$ and $\left.\mathrm{CH}_{2} \mathrm{~N}_{3}\right), 3.52-3.68\left(\mathrm{~m}, 10 \mathrm{H}, \mathrm{OCH}_{2}\right)$ 
Step 3 (from J. Mater. Chem., 2003, 13, 2471)

In a three-necked round bottomed flask under argon, the compound B-3 (30.40 g, 1.00 eq.) was dissolved in $100 \mathrm{~mL}$ of THF and the triphenylphosphine (47.46 g, $1.13 \mathrm{eq}$ ) was quickly added through a funnel, rinced with $160 \mathrm{~mL}$ of THF and the mixture was stirred at room temperature overnight. $100 \mathrm{~mL}$ of water were added, the THF was evaporated and the mixture was filtered. The filtrate was washed with toluene and evaporated under vacuum. The residue was dissolved in dichloromethane, dried with $\mathrm{MgSO}_{4}$, filtered and evaporated under vacuum to yield $24.55 \mathrm{~g}$ of a yellow liquid B-4. Yields $=94 \%$.

$\mathrm{RMN}{ }^{1} \mathrm{H}\left(\mathrm{CDCl}_{3}, 300 \mathrm{MHz}\right): 1.54$ (s large, $\left.2 \mathrm{H}, \mathrm{NH}_{2}\right), 2.79\left(\mathrm{t}, 2 \mathrm{H}, \mathrm{CH}_{2} \mathrm{~N}\right), 3.32\left(\mathrm{~s}, 3 \mathrm{H}, \mathrm{OCH}_{3}\right)$, 3.42-3.62 (m, $\left.10 \mathrm{H}, \mathrm{OCH}_{2}\right)$

Step 4 (from J. Mater. Chem., 2003, 13, 2471)

In a three-necked round bottomed flask placed in an ice bath, sodium (7.0 g, 2.4 eq.) was added to $200 \mathrm{~mL}$ of dried methanol under argon. Once the sodium has been consumed, the ice bath was withdrawn and thioacetic acid (20.0 g, 2.23 eq.) was added drop to drop. The commercial compound B-5 (24.26 g, 1.0 eq.) was dissolved in $100 \mathrm{~mL}$ of dried methanol and added drop to drop to the reaction medium which was then refluxed for 15 hours. After cooling at room temperature, the $\mathrm{pH}$ was adjusted to 3 thanks to $\mathrm{HCl} 6 \mathrm{M}$ and the product was extracted with dichloromethane. The organic layer was washed with water, dried on $\mathrm{MgSO}_{4}$, filtered and evaporated to give $22.6 \mathrm{~g}$ of a brown liquid. After purification by chromatography on silica gel, $16.4 \mathrm{~g}$ of a yellow liquid corresponding to compound B-6 were obtained. Yield $=69 \%$.

$\mathrm{RMN}{ }^{1} \mathrm{H}\left(\mathrm{CDCl}_{3}, 300 \mathrm{MHz}\right): 1.41\left(\mathrm{~m}, 2 \mathrm{H}, \mathrm{CH}_{2}\right), 1.61\left(\mathrm{~m}, 4 \mathrm{H}, \mathrm{CH}_{2}\right), 2.30\left(\mathrm{~s}, 3 \mathrm{H}, \mathrm{CH}_{3} \mathrm{CO}\right)$, 2.34 (t, 2H, $\left.\mathrm{CH}_{2} \mathrm{CO}\right), 2.85\left(\mathrm{t}, 2 \mathrm{H}, \mathrm{CH}_{2} \mathrm{~S}\right)$

Step 5 (from Org. Biomol. Chem., 2008, 6, 2118)

In a three-necked round bottomed flask under argon, compound B-6 (11.0 g, 1.0 eq.) was dissolved in $200 \mathrm{~mL}$ of dried $\mathrm{DMF}$ at $0^{\circ} \mathrm{C}$. Tripropylamine $(18.6 \mathrm{~mL}, 1.7$ eq.) was added, followed by IBCF drop to drop $(9.0 \mathrm{~mL}, 1.2$ eq.). The reaction medium was kept under stirring at $0^{\circ} \mathrm{C}$ for 1 hour. A solution made of compound B-4 (11.3 g, 1.2 eq.) and tripropylamine $(9.0 \mathrm{~mL}, 0.8$ eq. $)$ in $50 \mathrm{~mL}$ of DMF was prepared and added drop to drop. The ice bath was withdrawn and the mixture was kept under stirring for 24 hours. Ice was added to the reaction medium and the product was extracted with dichloromethane. The organic layer was thoroughly washed with water, dried with $\mathrm{MgSO}_{4}$, filtered and evaporated to yield 20.46 $\mathrm{g}$ of a clear yellow liquid. After purification by chromatography on silica gel, $10.0 \mathrm{~g}$ of product B-7 were obtained. Yield $=52 \%$.

$\mathrm{RMN}{ }^{1} \mathrm{H}\left(\mathrm{CDCl}_{3}, 300 \mathrm{MHz}\right): 1.39\left(\mathrm{~m}, 2 \mathrm{H}, \mathrm{CH}_{2}\right), 1.61\left(\mathrm{~m}, 4 \mathrm{H}, \mathrm{CH}_{2}\right), 2.16\left(\mathrm{t}, 2 \mathrm{H}, \mathrm{CH}_{2} \mathrm{CO}\right)$, $2.31\left(\mathrm{~s}, 3 \mathrm{H}, \mathrm{CH}_{3} \mathrm{CO}\right), 2.85\left(\mathrm{t}, 2 \mathrm{H}, \mathrm{CH}_{2} \mathrm{~S}\right), 3.38\left(\mathrm{~s}, 3 \mathrm{H}, \mathrm{OCH}_{3}\right), 3.41-3.66\left(\mathrm{~m}, 12 \mathrm{H}, \mathrm{OCH}_{2}\right)$

Step 6 (from J. Mater. Chem., 2003, 13, 2471)

Compound B-7 (2.0 g, 1.0 eq.) was dissolved in $20 \mathrm{~mL}$ of dried methanol and put in an ice bath. Acetyle chrloride $\left(4.25 \mathrm{~mL}, 10.0\right.$ eq.) was added drop to drop at $0^{\circ} \mathrm{C}$ and the mixture was left under stirring for 7 hours. Cold water was added to the reaction medium and the product was extracted with dichloromethane. The organic layer was washed with water, dried on $\mathrm{MgSO}_{4}$, filtered and evaporated to give $1.64 \mathrm{~g}$ of the colorless liquid B-8. Yield = 94 \%. 
$\mathrm{RMN}^{1} \mathrm{H}\left(\mathrm{CDCl}_{3}, 300 \mathrm{MHz}\right): 1.33(\mathrm{t}, 1 \mathrm{H}, \mathrm{SH}), 1.41\left(\mathrm{~m}, 2 \mathrm{H}, \mathrm{CH}_{2}\right), 1.63\left(\mathrm{~m}, 4 \mathrm{H}, \mathrm{CH}_{2}\right), 2.17(\mathrm{t}$,

$\left.2 \mathrm{H}, \mathrm{CH}_{2} \mathrm{CO}\right), 2.52\left(\mathrm{t}, 2 \mathrm{H}, \mathrm{CH}_{2} \mathrm{~S}\right), 3.37\left(\mathrm{~s}, 3 \mathrm{H}, \mathrm{OCH}_{3}\right), 3.41-3.66\left(\mathrm{~m}, 12 \mathrm{H}, \mathrm{OCH}_{2}\right)$ 
To evaluate the uncertainty of our NMR titration method, a series of tests have been performed in order to simulate the titration experiment.

First, a reference solution were carefully prepared with $100.4 \mathrm{mg}$ of D,L-alanine dissolved in $1.9901 \mathrm{~g}$ of $\mathrm{D}_{2} \mathrm{O}$ to yield a solution of 5.04 mass. \%. Then, 100.6, 66.9, 33.2 and $16.2 \mathrm{mg}$ of the reference solution were transferred in 4 NMR tubes. These amounts correspond to 5.57, $3.37,1.67,0.82 \mathrm{mg}$ of $\mathrm{D}$,L-alanine, respectively. $\mathrm{D}_{2} \mathrm{O}$ was evaporated from the tubes at $60{ }^{\circ} \mathrm{C}$ then $90{ }^{\circ} \mathrm{C}$ to leave only alanine in the tubes. $700 \mu \mathrm{L}(775.1 \pm 0.4 \mathrm{mg})$ of $\mathrm{D}_{2} \mathrm{O}$ were added to the dried tubes in order to reach the same volume in each tube. The concentration of alanine in each tube was:

$\begin{array}{ll}\text { Tube \# } & \text { [Alanine] }(\mathrm{mM}) \\ 1 & 89.3 \\ 2 & 54.0 \\ 3 & 26.8 \\ 4 & 13.1\end{array}$

The maximal errors on the mass and on the volume are $3 \%$ (i.e. $0.5 \mathrm{mg}$ for the lighter sample) and $2 \%$ (i.e. $1 \mathrm{~mm}$ of the filling height of the NMR tubes), respectively. Accordingly, the maximal error on the concentrations of NMR tubes is $5 \%$.

${ }^{1} \mathrm{H}$ NMR spectra were recorded for each tube, with conditions identical to those described in the experimental section for NMR titration of the ligands. The signal-to-noise ratio was evaluated from the area $6-8 \mathrm{ppm}$ free of any signal, and by integrating the $\mathrm{CH}$ quadruplet and the $\mathrm{CH}_{3}$ doublet with the ${ }^{13} \mathrm{C}$ satellites. It ranges from 8360 for the methyl signal of the most concentrated sample to 365 for the methyne signal of the most diluted one.

Then, we mimicked our titration process. Using the most concentrated tube (\#1: 89.3mM) as a calibration reference we obtain the following relations: $\operatorname{Int}(\mathrm{CH})=1.04 \mathrm{x}$ [alanine in $\mathrm{mM}]$ and $\operatorname{Int}\left(\mathrm{CH}_{3}\right)=3.18 \times$ [alanine in $\mathrm{mM}$. A simple cross-multiplication yields alanine concentrations for the other tubes:

$\begin{array}{lllll}\text { Tube \# } & \text { from the } \mathrm{CH} & \text { from the } \mathrm{CH}_{3} & \text { Actual concentration } & \text { Maximal Error } \\ 2 & \underline{54.58} & 54.36 & 54.0 & +1.1 \% \\ 3 & 26.99 & \underline{27.00} & 26.8 & +0.7 \% \\ 4 & 13.25 & \underline{13.34} & 13.1 & +1.8 \%\end{array}$

Using tube \#3 (26.8 $\mathrm{mM})$ as a calibration reference, we obtain $\operatorname{Int}(\mathrm{CH})=1.05 \times$ [alanine in $\mathrm{mM}$ ] and $\operatorname{Int}\left(\mathrm{CH}_{3}\right)=3.20 \times$ [alanine in $\mathrm{mM}$ ]. The crossmultiplication yields:

\begin{tabular}{|c|c|c|c|c|}
\hline Tube \# & from the $\mathrm{CH}$ & from the $\mathrm{CH}_{3}$ & Actual concentration & Maximal error ${ }^{\mathrm{a}}$ \\
\hline 1 & $\underline{88.68}$ & 88.69 & 89.3 & $-0.7 \%$ \\
\hline 2 & $\underline{54.06}$ & 54.03 & 54.0 & $+0.2 \%$ \\
\hline 4 & 13.12 & $\underline{13.25}$ & 13.1 & $+1.1 \%$ \\
\hline
\end{tabular}

${ }^{12}$ Observed for the underlined result 
For both cases, the maximal errors observed are lower than $2 \%$, actually smaller than the estimated accuracy of the test samples.

Our ${ }^{1} \mathrm{H}$ NMR titration procedure relies on the comparison (cross-multiplication) of the intensity recorded for the titrated solution versus the intensity for a reference tube whose concentration is known, for given signal, molecule and solvent. The tests performed on alanine show that the relative uncertainty of this measure is below $2.0 \%$. 